\title{
A mechanism underlying the neurotoxicity induced by sodium fluoride and its reversal by epigallocatechin gallate in the rat hippocampus: involvement of NrF2/Keap-1 signaling pathway
}

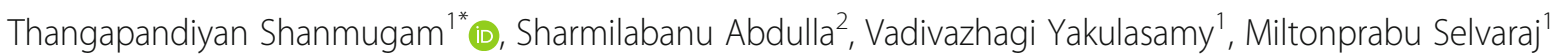 \\ and Ramesh Mathan ${ }^{2}$
}

\begin{abstract}
Background: Fluoride (FI) exposure engenders neurodegeneration and induces oxidative stress in the brain. Therefore, the mechanism of Fl-induced neurotoxic effects needs to be determined. The aim of this study was to investigate the neuroprotective effects of EGCG (40 mg/kg) on Fl (25 mg/kg/bw)-induced oxidative stress mediated neurotoxicity with special emphasis on the hippocampus (4 weeks).

Results: Fl-intoxicated rat shows an increased Fl concentration along with the decreased neurotransmitter (AChE, NP, DA and 5-HT) activity in the brain. The oxidative stress markers (ROS, TBARS, NO, and PC) was significantly increased with decreased enzymatic (SOD, CAT, GPx, GR, GST, and G6PD) and nonenzymatic antioxidants (GSH, TSH, and Vit.C) in the rat hippocampus. Moreover, results showed that increases in intrinsic and extrinsic apoptotic pathway leading to DNA damage and cell death were also proved by the immunohistochemical, histological, and ultra-structural studies in the Fl-treated rat hippocampus. In this context, pre-administration of EGCG significantly improved the oxidative stress, biochemical changes, cellular apoptotic and histological alternations by FI in the hippocampus of rats.
\end{abstract}

Conclusions: These results confirmed the EGCG supplementation might attenuate the Fl-induced neurotoxicity via Nrf2/Keap1 signaling pathway in the rat hippocampus.

Keywords: Fluoride, Epigallocatechin gallate, ROS, Nrf2/Keap1, Rat, Hippocampus

\section{Background}

Fluoride $(\mathrm{Fl})$ is a potent central nervous system toxin and affects the brain function even at low doses (Mullenix, Denbensten, Sehunior, \& Kernan, 1995). The research on $\mathrm{Fl}$ and the brain that have been studied in humans in India, China, Iran, and Mexico showed that high levels of Fl exposure were associated with IQ deficits in children (NRC, 2006). The animal studies have also documented

\footnotetext{
* Correspondence: s.thangapandiyanphd@gmail.com

'Department of Zoology, Annamalai University, Annamalai Nagar 608002,

Chidambaram, India

Full list of author information is available at the end of the article
}

the considerable evidence on the direct toxic effects of $\mathrm{Fl}$ on the brain, even at the low level of $1 \mathrm{ppm} \mathrm{Fl}$ in water (Varner, Jensen, Horvath, \& Isaacson, 1998). These effects include a reduction in nicotinic acetylcholine receptors, reduction in lipid content, impaired anti-oxidant defense, damage to the hippocampus, Purkinje cells and accumulation of $\mathrm{Fl}$ in the pineal gland and the formation of betaamyloid plaques (NRC, 2006). Earlier epidemiological studies and animal experiments have also demonstrated that the intelligence of children and animals exposed to high levels of fluoride were severely impaired, especially with the symptoms of decreased learning and memory capacity (Lu et al., 2000). 
$\mathrm{Fl}$ intoxication leads to fluorosis, a common disorder in emerging countries; it cause injury not only to skeletal tissue and teeth but also to soft tissues like the brain, liver, kidney, and spinal cord (Nabavi et al., 2012). Fl can easily be distributed in the body through blood circulation, crossing the cellular membrane, and its subsequent accumulation leads to cellular damage and apoptosis (Bouaziz, Ben Amara, Essefi, Croute, \& Zeghal, 2010). Fl-induced neurodegeneration can occur when $\mathrm{Fl}$ penetrates the brain through the blood-brain barrier (Madhusudhan, Basha, Begum, \& Ahmed, 2009), because Fl ions are more electronegative in nature. In a fatal stage, $\mathrm{Fl}$ accumulation can lead to alterations in growth, cell differentiation, and subcellular organization in the brain cells. In the Fl-contaminated area, the exposed subject demonstrates neurological disorders such as partial paralysis of arms and legs, headache, visual disturbances, and mental retardation (Eraslan, Kanbur, \& Silici, 2007).

The hippocampus is one of the most important region in the brain responsible for the formation of new memories and helps us to navigate. $\mathrm{Lu}, \mathrm{Lu}$, and Jing (2000) reported that the hippocampus is considered to be one of the crucial neurotoxic target sites attacked by $\mathrm{Fl}$ as evidenced from numerous animal experimental models (Mullenix, Denbesten, Schunior, \& Kernan, 1995). The hippocampus contains high levels of glucocorticoid receptors, which makes it more vulnerable to oxidative stress than the other regions of the brain (Joels, 2008). Recently, apoptosis and inflammation have been demonstrated to play an imperative role in Fl-induced neurotoxicity in the hippocampus of rats. Fl can induce a variety of apoptotic cell types (Tokunaga et al., 2003; Ming, Aiguo, Tao, \& Ping, 2008) possibly ascribed to the involvement of Fl-induced oxidative stress (Anuradha, Kanno, \& Hirano, 2001).

The free radical production is known to be one of the most important mechanisms of Fl-induced neurotoxicity (Bhatnagar, Rao, \& Sushma, 2002). The central nervous system had vulnerability to free radical damage due to elevated oxidative metabolic rate and enriched content of unsaturated lipids, as well as its eminent rate of free radical generation derived from neurotransmitters metabolism, and poor radical scavenging mechanisms (Chong, Li, \& Maiese, 2005). The oxidative stress-induced free radical damage has been observed in soft tissues such as the liver, kidney, brain, and testes where animals exposed to $\mathrm{Fl}$ (Thangapandiyan \& Miltonprabu, 2013; Thangapandiyan \& Miltonprabu, 2014; Nabavi et al., 2012; and Shanthakumari, Srinivasalu, \& Subramanian, 2004). Fl exposure decreases the intracellular glutathione levels and can inhibit the activity of several antioxidant enzymes such as superoxide dismutase (SOD), glutathione peroxidase, and catalase (Chlubek \& Poland, 2003). A variety of mechanisms has been proposed to explain Fl-induced neurotoxicity. Numerous studies have shown that $\mathrm{Fl}$ induces the production of reactive oxygen species in the brain (Madhusudhan et al., 2009; Nabavi et al., 2012).

There are several reports evidencing the neuroprotective effects of antioxidant agents against Fl-induced toxicity in neural systems (Eraslan et al., 2007). Recent studies have evaluated the protective effects of herbal constituents such as epigallocatechin gallate, curcumin, and quercetin as antioxidant agents against neurological diseases induced by reactive oxygen species (Kumar \& Kumar, 2009; Nabavi et al., 2012). It has been also reported that the antioxidant activity of plant constituents is mainly related to its natural compounds, such as flavonoids and phenolic acids (Nabavi, Eslami, Moghaddam, \& Nabavi, 2011). Green tea is a popular beverage used worldwide for it is a variety of pharmacological property such as antioxidant, antimutagenic, antiproliferative, and anticarcinogenic properties and neuroprotective activities (Lee, Kim, \& Kim, 2000). Chemically, green tea contains many polyphenolic compounds, commonly known as catechins. Among them, epigallocatechin gallate (EGCG) (Fig. 1) is one of the versatile polyphenol known for its powerful antioxidant property, protecting cells against freeradical DNA damage, inhibition of lipid peroxidation and protein oxidation (Thangapandiyan \& Miltonprabu, 2014).

The NrF2/Keap-1 signaling pathway plays a key role in the regulation cell's survivability by improving natural antioxidant levels in the body under stress condition. Taking in to account, the previous studies demonstrated that the polyphenols from green tea, especially EGCG, significantly improved the quality of wound healing and remarkably suppressed the hepatic, kidney, and pulmonary toxicity (Thangapandiyan \& Miltonprabu, 2014; Thangapandiyan \& Miltonprabu, 2014; Thangapandiyan, Miltonprabu, \& Senthilraja, 2016). However, there is a paucity of data available on the neuroprotective action of EGCG against Fl-induced hippocampal neurotoxicity in rats. Moreover, this study attempted to investigate the possible mechanism of Nrf2-Keap1 signaling pathway underlying the protective effects of EGCG

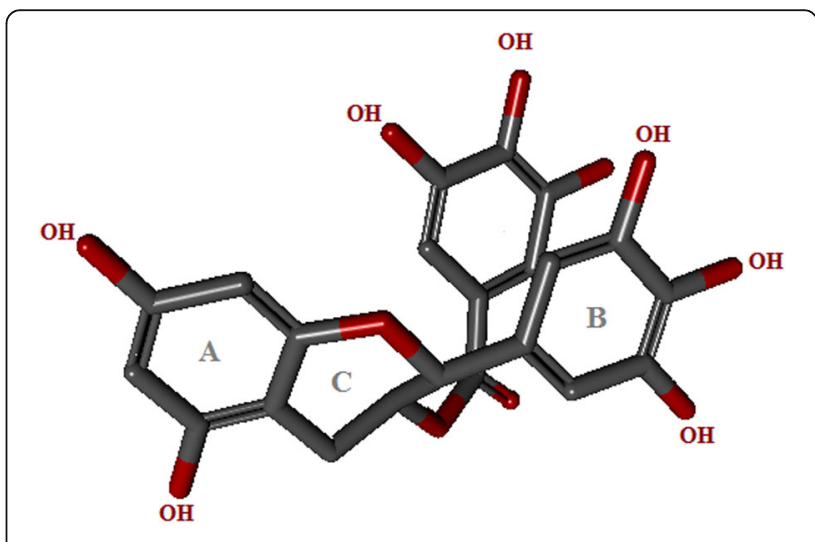

Fig. 1 Chemical structure of EGCG $\left(\mathrm{C}_{22} \mathrm{H}_{18} \mathrm{O}_{11}\right)$ 
against Fl-induced oxidative changes, apoptotic and inflammatory action in the brain with special emphasis on the hippocampus region of rats.

\section{Methods}

Chemicals

Sodium fluoride (NaF), Epigllaocatechin gallate (EGCG), $1,1^{\prime}, 3,3^{\prime}$ - tetramethoxy propane, and bovine serum albumin were purchased from Sigma Chemical Co., St. Louis, MO, USA. Superscript-III Reverse Transcriptase was purchased from Invitrogen, (USA), and PCR Ready Mix DNA Polymerase was purchased from KAPA Biosystem (USA). Bax, Bad, Bcl-2, caspase-3, 8, 9, and NF-kB, TNF- $\alpha$ and Fas antibodies were purchased from Santa-cruz Biotechnology, Inc., USA. All other chemicals and solvents were of certified analytical grade and purchased from S.D. Fine Chemicals, Mumbai or Himedia Laboratories Pvt. Ltd., Mumbai, India. Reagent kits were obtained from span Diagnostics, Mumbai, India. Chemical structure of EGCG is shown in Fig. 1.

\section{Animals and diet}

Healthy adult male albino rats of Wistar strain, bred and reared in Central Animal House, Department of Experimental Medicine, Rajah Muthiah Medical College, and Annamalai University, were used for the experiment. Males were preferred to avoid complications of the estrous cycle. Animals of equal weight (160-180 g) were selected and housed in polypropylene cages lined with husk and kept in a semi natural light/dark condition $(12 \mathrm{~h}$ light/12 $\mathrm{h}$ dark). The animals had free access to water and were supplied with standard pellet diet (Amrut Laboratory Animal Feed, Pranav Agro Industries Ltd., Bangalore, India), constitution of protein (22.21\%), fat (3.32\%), fiber (3.11\%), balanced with carbohydrates (>67\%), vitamins, and minerals. All animals received human care according to the criteria outlined in the Guide for the care and use of Laboratory Animals. Animal handling and experimental procedures were approved by the Institutional Animal Ethics Committee (Registration Number: 952/2012/ CPCSEA), Annamalai University, Annamalai nagar, India.

\section{Experimental design}

Table 1 shows the experimental groups, NaF and EGCG concentration, and total duration of the study. $\mathrm{NaF}$ was administered orally at a dose of $25 \mathrm{mg} / \mathrm{kg}$ body wt/day for 4 weeks, which was $1 / 10$ of the oral $\mathrm{LD}_{50}$ values in rats (Chinoy, 1991). In the experiment, a total of 24 rats were used. The rats were randomly divided into four groups of six animals in each. Control rats (group 1) received the vehicles only; experimental rats were subdivided into two groups (3 and 4). Drug control (group 2) received the EGCG (dissolved in 10\% of Tween 80) alone. A pilot study was conducted with three different doses of EGCG $(20,40$, and $80 \mathrm{mg} / \mathrm{kg})$ to determine the dose-dependent effect of EGCG in rats (Thangapandiyan \& Miltonprabu, 2013). After 4 weeks of experiment, it was observed that EGCG pretreatment at the doses of 20,40 , and $80 \mathrm{mg} / \mathrm{kg}$ significantly $(p<0.05)$ recovered the rat from Fl-induced biochemical and histological changes (data have not shown). Forty milligrams per kilogram of EGCG showed higher significant effect than the lower 20 and higher doses $80 \mathrm{mg} / \mathrm{kg}$. Hence, we have chosen the intermediate dose $(40 \mathrm{mg} / \mathrm{kg})$ of EGCG as an effective dose against $\mathrm{Fl}$ toxicity for further studies.

The animals were maintained in their respective groups for 4 weeks. Food and fluid intake and body weight were measured periodically. At the end of the experimental period, all animals were anesthetized. Twenty minutes later, the anesthetized rats were sacrificed. Animals were pinned onto a dissection board and the peritoneal cavity was opened. Thus, immediately, the hippocampal tissues were removed for histological and immunohistochemical and other investigations. The blood was collected and centrifuged at $2000 \times g$ for $20 \mathrm{~min}$ to prepare plasma. Brain tissues were excised washed and homogenized in $0.1 \mathrm{M}$ Tris-HCl-0.001 M EDTA buffer (pH 7.4) and centrifuged at $12,000 \times g$ for $30 \mathrm{~min}$ at $4{ }^{\circ} \mathrm{C}$. The supernatant was collected and used for the experiments.

\section{Biochemical assays}

\section{Determination of neurotransmitters in the brain}

Ten percent brain homogenate $(w / v)$ was prepared in $0.25 \mathrm{M}$ sucrose for determining the neurotransmitters' activity of acetyl cholinesterase (AChE) using acetylthiocholine as substrate as described in the reported method of Ellman, Courtney, Andres, and Featherstone (1961). The frozen brain tissue samples were weighed and homogenized in acidified butanol. Dopamine (DA),

Table 1 The experimental design

\begin{tabular}{|c|c|c|c|}
\hline Groups & Concentration and volume of FI/EGCG/vehicle administrated & $\begin{array}{l}\text { Treatment } \\
\text { period }\end{array}$ & Sacrifice \\
\hline Group I (Control) & $0.5 \mathrm{ml}$ of slain solution administrated as vehicle/day & 4 weeks & 29th day \\
\hline Group II (EGCG alone) & EGCG $40 \mathrm{mg} / \mathrm{kg}$ bw $(1.6 \mathrm{ml})$ per day by intragastric administration & 4 weeks & 29th day \\
\hline Group III (FI as NaF alone) & $\mathrm{Fl}$ as NaF $25 \mathrm{mg} / \mathrm{kg}$ bw $(2.5 \mathrm{ml})$ per day by intragastric administration & 4 weeks & 29th day \\
\hline Group IV (Pre-treatment with EGCG followed by NaF) & $\begin{array}{l}\text { EGCG } 40 \mathrm{mg} / \mathrm{kg} \text { bw }(1.6 \mathrm{ml}) \text { administrated } 30 \text { min before administration } \\
\text { of } \mathrm{NaF}(2.5 \mathrm{ml}) \text { per day by intragastric administration }\end{array}$ & 4 weeks & 29th day \\
\hline
\end{tabular}


norepinephrine (NE), and 5-hydroxytryptamine (5-HT) were estimated according to the method of Jacobwitz and Richardson (1978).

\section{Estimation of $\mathrm{Fl}$ concentration}

Fl levels in the brain were determined by the method of Birkel (1970) with required modifications (Vani \& Reddy, 2000) and are expressed as microgram of $\mathrm{Fl} \mathrm{g-1}$ dry tissue. The whole brain was dissected out, pooled, homogenized, and dried for $24 \mathrm{~h}$ at $105{ }^{\circ} \mathrm{C}$. About $200 \mathrm{mg}$ of the dry sample was dissolved in an acid mixture (equal parts of $11.6 \mathrm{M}$ perchloric acid and $14.3 \mathrm{M}$ nitric acid) and neutralized with citrate buffer to a $\mathrm{pH} 5.5$ with an alkaline mixture of $7.8 \mathrm{M}$ sodium hydroxide and $1.0 \mathrm{M}$ trisodium citrate. The process was carried out in a closed compartment. The sample thus obtained was used after appropriate dilutions for recording the Fl content on a fluorimeter (Orion R 94-09).

\section{Estimation of brain ROS and oxidative stress markers}

A modified version of a previously described assay for the intracellular conversion of nitro blue tetrazolium (NBT) to formazan by superoxide anion was used to measure the generation of reactive oxygen species (Vrablic, Albright, Craciunescu, Salganik, \& Zeisel, 2001). Briefly, $200 \mu \mathrm{l}$ NBT $(1.0 \mathrm{mg} / \mathrm{ml})$ was added to the tissue homogenates from each of the groups, followed by additional incubation for $1 \mathrm{~h}$ at $37^{\circ} \mathrm{C}$. Solutions were then treated with $100 \mu \mathrm{K} \mathrm{KOH}$ (2 M). NBT reduced/g tissue expressed in lmol was determined through spectrophotometry. If radical-scavenging compounds were present in the tissue, less formazan blue would be formed, thus decreasing the absorption at $570 \mathrm{~nm}$. Lipid peroxidation was estimated spectrophotometrically by measuring thiobarbituric acid reactive substances by the method of Niehiaus and Samuelsson (1968). The assay of nitrite/nitrate, as an indirect measure of $\mathrm{NO}$ production in the tissue homogenates, was done according to the method of
Berkels, Purol-Schnabel, and Roesen (2004) Protein carbonyl content was determined by the method of Levine, Garland, and Oliver (1990).

\section{Determination of non-enzymatic and enzymatic antioxidants}

Reduced glutathione was determined by the method of Ellman (1959). Total sulfhydryl groups were measured by the method of Ellman (1959). Vitamin C concentration was measured by Omaye, Turnbull, and Sauberlich (1979). Superoxide dismutase activity was determined by the method of Kakkar, Das, and Viswanathan (1984). The activity of catalase was determined by the method of Sinha (1972). Glutathione peroxidase activity was estimated by the method of Rotruck, Rope, and Ganther (1973). Glutathione reductase was assayed by the method of Horn and Burns (1978). Glutathione-S-transferase was assayed by Habig, Pabst, and Jakpoly (1974). The estimation of glucose-6-phosphate dehydrogenase was measured by the method of Beutler (1978). Protein in the tissue homogenate was measured by Lowry, Rosebrough, Farr, and Randall (1951).

\section{RT-PCR analysis for the brain hippocampus}

Total RNA was isolated from the hippocampus using TRI reagent following the method of Chomczynski and Sacchi (1987). One microgram of total RNA was subjected to twostep RT-PCR First strand reaction: Complementary DNA (cDNA) is made from mRNA template using dNTPs \& Reverse transcriptase (Superscript-III Reverse Transcriptase, Invitrogen, USA). The components were combined with a DNA primer in a reverse transcriptase buffer for an hour at $37^{\circ} \mathrm{C}$. Second strand reaction: After the reverse transcriptase reaction was complete, cDNA has been generated from the original single-strand mRNA, and standard PCR was initiated (PCR Ready Mix DNA polymerase was purchased from KAPA-Biosystem, USA). PCR primers and conditions used in this study have been tabulated (Table 2).

Table 2 The list of primers used for RT-PCR

\begin{tabular}{|c|c|c|c|c|c|}
\hline Gene Accession no. & Gene descriptio & $\begin{array}{l}\text { Gene } \\
\text { symbol }\end{array}$ & Forward & Reverse & $\begin{array}{l}\text { Product } \\
\text { size }\end{array}$ \\
\hline NM_022698.1 & Bcl-2-associated death promoter & Bad & CAGGCAGCCAATAACAGTCA & ССАТСССТТСТТТТССТСА & 100 \\
\hline NM_ 031632 & Bax: Bcl-2-associated $X$ protein & Bax & GACACCTGAGCTGACCTTGG & GAGGAAGTCCAGTGTCCAGC & 310 \\
\hline NM_016993.1 & B-cell /lymphoma 2 & $\mathrm{BCl} 2$ & GGGATGCCTTTGTGGAACTA & СTCACTTGTGGCCCAGGTAT & 138 \\
\hline NM_012675.2 & Tumor necrosis factor superfamily-2 & TNF-a & CTCCCAGAAAAGCAAGCAAC & CGAGCAGGAATGAGAAGAGG & 210 \\
\hline NM_342346.3 & Nuclear factor-kB & $\mathrm{NF}-\mathrm{kB}$ & CGAGCAGGAATGAGAAGAGG & CATCTTCAACATGGCAGACGACGA & 130 \\
\hline NM_139194.2 & TNF receptor superfamily- 6 & Fas & TGCACCAACCTGCCATCCGT & ATTCTGGGTCCGGGTGCAGT & 139 \\
\hline NM_022277.1 & Cysteine-aspartic proteases 8 & Cas8 & GCGACAGGTTACAGCTCTCC & GCAGCCTCTGAAATAGCACC & 180 \\
\hline NM_031632.1 & Cysteine-aspartic proteases 9 & Cas9 & CTGGCCCAGTGTGAATACCT & CTCAGTCAACTCCTGGGCTC & 233 \\
\hline NM_012922.2 & Cysteine-aspartic proteases 3 & Cas 3 & AGTTGGACCCACCTTGTGAG & AGTCTGCAGCTCCTCCACAT & 298 \\
\hline NM_017008.3 & Glyceraldehde3 phosphate dehydrogenase & Gapdh & GCCAAGGCTGTGGGCAAGGT & GAGCAATGCCAGCCCCAGCA & 29 \\
\hline
\end{tabular}


The amplified products were separated by electrophoresis on 2\% Agarose gel and identified by ethidium bromide staining. Specificity was confirmed by the size of the amplified products with reference of $100 \mathrm{bp}$ DNA ladder (Chromus Biotech, Chennai) and the band intensities were quantified by Quantity One Software (Bio-Rad, USA).

\section{Western blotting analysis}

Protein expression was carried out as per the standard protocol. The hippocampus tissue was homogenized with RIPA containing protease inhibitors (1 mM PMSF and $0.5 \mathrm{mg} / \mathrm{ml}$ each of leupeptin and apoprotinin), and protein concentrations were determined by the method of Lowry et al. (1951). The samples were solubilized in a reducing loading buffer (62.5 mM Tris, pH 6.8, $6 \mathrm{M}$ urea, 10\% glycerol, $2 \%$ sodium dodecyl sulfate (SDS), $0.003 \%$ bromophenol blue, 5\% 2-mercaptoethanol), electrophoresed in 10\% SDS polyacrylamide gels and then transferred onto PVDF membranes. The membranes were incubated with primary antibodies (diluted according to the manufacturer's instruction) followed by the incubation with Horseradish peroxidase-conjugated anti-mouse IgG or anti-rabbit IgG secondary antibody. Finally, protein bands were visualized on Chemi Doc Imaging System, Bio-Rad (USA), using an enhanced chemiluminescence system (ECL, Pierce, USA).

\section{DNA fragmentation}

The hippocampus tissue (100 mg) was homogenized in $1 \mathrm{ml}$ 19 suspension buffer in $2 \mathrm{ml}$ microcentrifuge tube. After homogenization, $5 \mu \mathrm{l}$ RNase solutions (Conc. $10 \mathrm{mg} / \mathrm{ml}$ ) was added, mixed five to six times by inverting the vial and incubated at $65^{\circ} \mathrm{C}$ for $10 \mathrm{~min}$ with intermittent mixing.

After incubation, $1 \mathrm{ml}$ lysis buffer was added, mixed, incubated at $65{ }^{\circ} \mathrm{C}$ for $15 \mathrm{~min}$, and then cooled at RT. After incubation, the lysate was centrifuged at $13,000 \mathrm{rpm}$ for $1 \mathrm{~min}$ at RT. To the supernatant, equal volume of isopropanol was added to each vial, mixed well, and centrifuged at $13,0009 \mathrm{~g}$ for $15 \mathrm{~min}$ at RT. To the pellet, $0.5-1 \mathrm{ml}$ of $70 \%$ ethanol was added and centrifuged at $13,0009 \mathrm{~g}$ for $15 \mathrm{~min}$ at $\mathrm{RT}$, and this was repeated again. The pellet was dried at $37^{\circ} \mathrm{C}$ for $10 \mathrm{~min}$. Fifty microliters of autoclaved milliQ water was added, and the DNA was suspended by placing the vial at $4{ }^{\circ} \mathrm{C}$ overnight. The isolated DNA were resolved by electrophoresis through a $1 \%$ agarose gel and stained with ethidium bromide. The resolved fragments of DNA in the agarose gel were scanned with a Gel Doc image scanner (Bio-Rad, USA).

\section{Immunohistochemistry}

Harvested hippocampal tissues were fixed in 10\% neutral buffered formalin, embedded in paraffin, and sectioned at $5 \mathrm{~lm}$ thickness. Immunocytochemical reactions were performed according to the $\mathrm{ABC}$ technique described by Hsu et al., (1981) (43). The procedure involved the following steps: (1) endogenous peroxidase activity was inhibited by $3 \% \mathrm{H}_{2} \mathrm{O}_{2}$ in distilled water for $30 \mathrm{~min}$; (2) the sections were washed in distilled water for $10 \mathrm{~min}$; (3) nonspecific binding of antibodies was blocked by incubation with normal goat serum (DAKO X 0907, Carpinteria, CA) with PBS, diluted 1:4; (4) the sections were incubated with a specific rabbit polyclonal anti-caspase-3 antibody (Cat. \# RB-1197-P, Neomarkers, USA), diluted 1:50 for $1 \mathrm{~h}$, and then kept at room temperature; (5) the sections were washed in PBS for $3 \times 3 \mathrm{~min}$; (6) the sections were incubated with ABC complex (DAKO LSAB $2 \mathrm{Kit}$ ); (7) the sections were washed in PBS for $3 \times 3 \mathrm{~min}$; (8) peroxidase was detected with diaminobenzidine as substrate; (9) the sections were washed in tap water for $10 \mathrm{~min}$ and then dehydrated; (10) nuclei were stained with hematoxylin; and (11) the sections were mounted in DAKO paramount.

\section{Histopathalogy}

Biopsies from the hippocampal tissues of the rats were harvested, and tissue fragments were fixed in 10\% neutral buffered formalin solution, embedded in paraffin, sectioned at 5- $\mu \mathrm{m}$ thickness, and then stained with hematoxylin and eosin (H\&E). The preparations were evaluated by means of a bright-field microscope and photographed (Optiphot 2; Nikon, Tokyo, Japan).

\section{Electron microscopy studies}

For electron microscopy, the hippocampal tissue was fixed with $2.5 \%$ glutaraldehyde in $0.1 \mathrm{M}$ sodium phosphate buffer ( $\mathrm{pH} 7.2)$ for $3 \mathrm{~h}$ at $4{ }^{\circ} \mathrm{C}$, washed in the same buffer for $1 \mathrm{~h}$ at $4{ }^{\circ} \mathrm{C}$, and post-fixed with $1 \%$ osmium tetraoxide in sodium phosphate buffer for $1 \mathrm{~h}$ at $4{ }^{\circ} \mathrm{C}$. The tissues were then dehydrated in graded series of ethanol starting at 50\% each step for $10 \mathrm{~min}$ and after two changes in propylene oxide. The tissue specimens were embedded in araldite. Ultrathin sections were prepared with Mg-uranyl acetate and lead citrate for the electron microscopic (Jeol JEM 1010) evaluation.

\section{Statistical analysis}

All statistical analyses were carried out using SPSS statistical software (SPSS for windows, version 11.0). All data were presented in mean $( \pm)$ standard deviations (S.D). Differences between groups were estimated using a one-way analysis of variance followed by Duncan's multiple range tests. Values of $P<0.05$ were considered as significant.

\section{Results}

Effect of EGCG on body weight, organ weight, and relative organ weight food and water intake

Table 3 depicts the effects of Fl and EGCG on body weight gain, food and water intake, and relative brain 
Table 3 Changes in body weight, body weight gain, food intake, water intake, and organ-body weight ratio in control and experimental rats

\begin{tabular}{|c|c|c|c|c|c|}
\hline \multicolumn{2}{|l|}{ Groups } & \multirow{2}{*}{$\frac{\text { Control }}{180.3 \pm 1.20}$} & \multirow{2}{*}{$\frac{E G C G}{183.4 \pm 3.2}$} & \multirow{2}{*}{$\begin{array}{l}\mathrm{Fl} \\
184.6 \pm 4.2\end{array}$} & \multirow{2}{*}{$\frac{\mathrm{EGCG}+\mathrm{FI}}{185.3 \pm 2.4}$} \\
\hline Body weight & Initial (g) & & & & \\
\hline & Final (g) & $223.6 \pm 2.3$ & $225.2 \pm 3.7$ & $173.4 \pm 4.8$ & $220.8 \pm 5.3$ \\
\hline \multicolumn{2}{|c|}{ Organ weight (g) brain } & $1.70 \pm 0.04^{a}$ & $1.71 \pm 0.05^{\mathrm{a}}$ & $1.50 \pm 0.02^{b}$ & $1.67 \pm 0.03^{c}$ \\
\hline \multicolumn{2}{|c|}{ Food intake (g/100 g bw/day) } & $13.18 \pm 0.72^{\mathrm{a}}$ & $14.76 \pm 0.81^{a}$ & $09.12 \pm 0.50^{b}$ & $13.29 \pm 0.70^{c}$ \\
\hline \multicolumn{2}{|c|}{ Water intake (mL/rat/day) } & $19.24 \pm 2.30^{\mathrm{a}}$ & $20.30 \pm 2.25^{a}$ & $14.18 \pm 1.18^{b}$ & $18.27 \pm 2.46^{\mathrm{C}}$ \\
\hline \multicolumn{2}{|c|}{ Organ-body weight ratio (\%) brain } & $0.72 \pm 0.007^{a}$ & $0.71 \pm 0.008^{a}$ & $0.49 \pm 0.004^{b}$ & $0.64 \pm 0.005^{c}$ \\
\hline
\end{tabular}

Values are given as mean \pm SD from six rats in each group. ${ }^{a}$, $b$, and ${ }^{c}$ Values with different superscript letters $(a-c)$ in the same row differ significantly at $p<0.05$ (DMRT)

aalues do not differ significantly from control and EGCG group at $(p<0.05)$

${ }^{b}$ Values differ significantly from control and drug control group at $(p<0.05)$

'Values differ significantly from $\mathrm{Fl}$ group at $(\mathrm{P}<0.05)$

weight in control and experimental rats. In Flintoxicated rats, water and pellet diet consumption significantly $(p<0.05)$ decreased with a decrease in body weight. A significant $(p<0.05)$ decrease in relative brain weight were also recorded in Fl-treated rats when compared with control rats. Treatment with EGCG effectively attenuated the Fl-induced alterations in food and water intake, body weight, and relative brain weight, when compared with Fl-treated rats. Administration of EGCG alone to rats did not show any alterations in these parameters and did not differ significantly from control group.

\section{Effect of EGCG on the activities of neurotransmitters}

The levels of neurotransmitters AChE, NP, DA, and 5HT of control and experimental rats are shown in Fig. 2. The levels of neurotransmitters AChE (Fig. 2a), NP (b), DA (c), and 5-HT (d) in the brain significantly $(p<0.05)$ decreased in $\mathrm{Fl}$-intoxicated rats when compared to

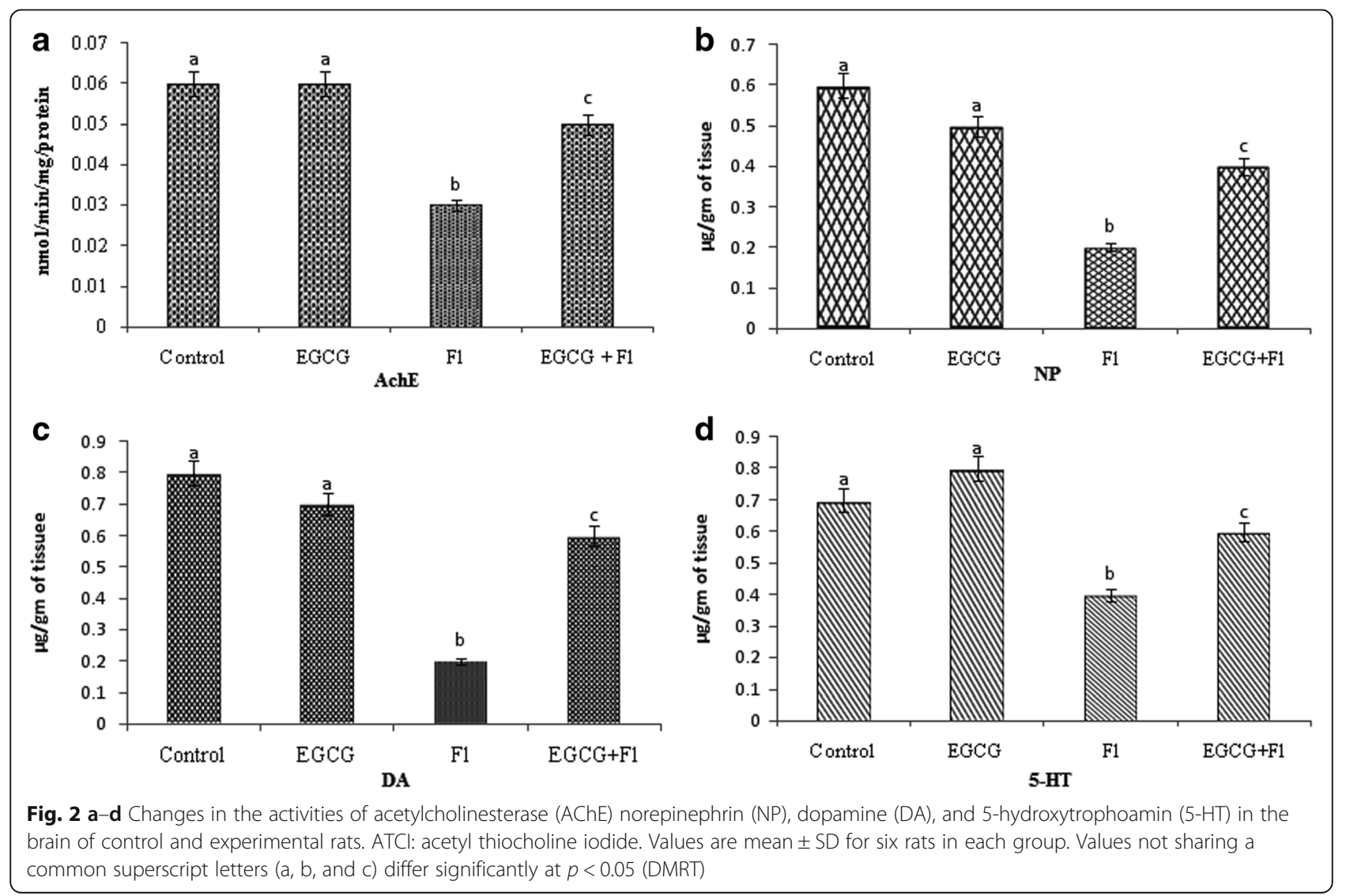


the control rats whereas pre-administration of EGCG in Fl-intoxicated rats significantly $(p<0.05)$ increased the neurotransmitters' levels when compared to the Fl-treated rats.

\section{Effect of EGCG on FI concentration}

Figure 3 shows the concentration of $\mathrm{Fl}$ in the brain of control and experimental rats. Accumulation of Fl significantly $(p<0.05)$ increased in the Fl-treated brain when compared with control rats. Pre-administration of EGCG significantly $(p<0.05)$ reduced the accumulation of $\mathrm{Fl}$ in Fl-intoxicated rats when compared with Fl-alone-treated rats. There are no significant $(p<0.05)$ changes in the accumulation of Fl in EGCG-alone-treated rats when compared with control rats.

\section{Effect of EGCG on oxidative stress results}

Figure 4 shows the levels of the hippocampus oxidative stress markers in control and experimental rats. The levels of ROS, TBARS, NO, and PC were significantly $(p<0.05)$ increased in Fl-intoxicated rats when compared with control rats. Pre-administration of EGCG significantly $(p<0.05)$ decreased the levels of oxidative stress markers when compared with $\mathrm{Fl}$-alone-treated rats. There is no significant changes that occur between control and EGCG-alone-treated rats.

\section{Effect of EGCG on non-enzymatic antioxidants}

The effect of EGCG on the activities of GSH, TSH, and vitamin $\mathrm{C}$ in the hippocampus of control and experimental rats was illustrated in Fig. 5. The levels of non-enzymatic antioxidants were significantly $(p<0.05)$ decreased in the hippocampus of Fl-intoxicated rats when compared with control rats. Pre-administration of EGCG significantly $(p<0.05)$ increased the levels of non-enzymatic antioxidants in Fl-treated rats when compared with Fl-alonetreated rats. The levels of non-enzymatic antioxidants

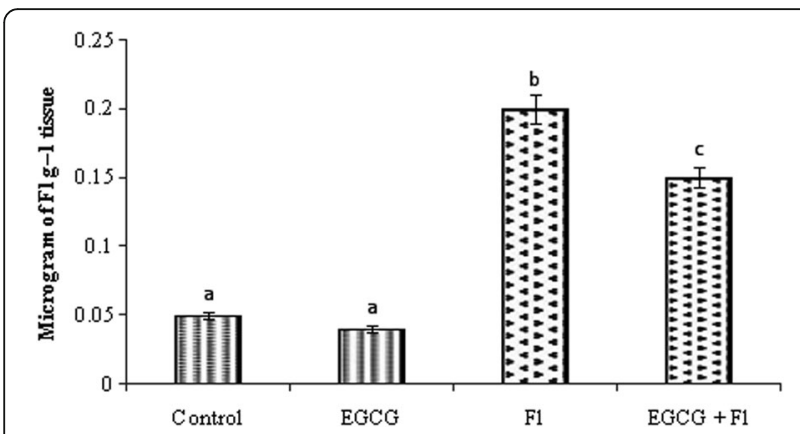

Fig. 3 Effect of EGCG on the concentration of FI in the brain of the control and experimental rats. Values are mean \pm SD for 6 rats in each group. Values not sharing a common superscript letter $(a, b$, and $c)$ differ significantly at $p<0.05$ (DMRT) found in EGCG-alone-treated rats similar to that of control rats.

\section{Effect of EGCG on enzymatic antioxidants}

The activities of enzymatic antioxidants such as SOD, CAT, GP, GST, GR, and G6PD in the hippocampus of control and experimental rats are illustrated in Table 4. Fl-treated rats significantly $(p<0.05)$ decreased levels of enzymatic antioxidants in the hippocampus when compared to the control rats, whereas the preadministration of EGCG in Fl-treated rats significantly $(p<0.05)$ increased the activities of enzymatic antioxidants when compared to the $\mathrm{Fl}$-alone-treated rats. EGCG-alone-treated rats did not showed any changes in the activities of enzymatic antioxidants when compared to control rats.

\section{Effects of EGCG on neuronal apoptotic markers}

The protective effect of EGCG on pro-apoptotic gene and protein of control and Fl-treated rats is shown in Figs. 6 and 7. A significant $(p<0.05)$ increase in the levels of pro-apoptotic gene (Fig. 6) and protein (Fig. 7) with significant $(p<0.05)$ decrease in the levels of antiapoptotic gene and protein (Bcl-2) was observed in Fl-intoxicated rats when compared with control. Preadministration of EGCG to Fl-intoxicated rats significantly $(p<0.05)$ decreased pro-apoptotic gene and protein with significant $(p<0.05)$ increased anti-apoptotic gene and protein (Bcl-2) when compared to Fl-alonetreated rats. These alterations confirm the protective role of EGCG on neuronal apoptosis via blocking intrinsic signaling pathway.

\section{Effects of EGCG on hippocampus inflammatory markers}

The protective effect of EGCG on inflammatory gene and protein of control and experimental rats are shown in Figs. 8 and 9. There was a significant $(\mathrm{p}<0.05)$ increase in the levels of inflammatory gene (Fig. 8) and protein (Fig. 9) observed in Fl-intoxicated rats when compared with control. Pre-administration of EGCG to Fl-intoxicated rats significantly $(p<0.05)$ decreased inflammatory gene and protein when compared with Flalone-treated rats. EGCG supplemented group confirming the protection of the hippocampus from Fl-induced apoptosis via extrinsic pathway also.

\section{Effects of EGCG on Fl-induced apoptosis}

The pro-caspases are converted to caspases when there is an apoptotic signal. These caspases are mediators of apoptosis. In this study, we estimated the gene and protein expression of Casp 8, Casp9, and Casp3 in control and experimental rats. All the caspases' gene (Fig. 10) and protein expression (Fig. 11) were significantly $(p<0.05)$ increased in Fl-treated rats when 


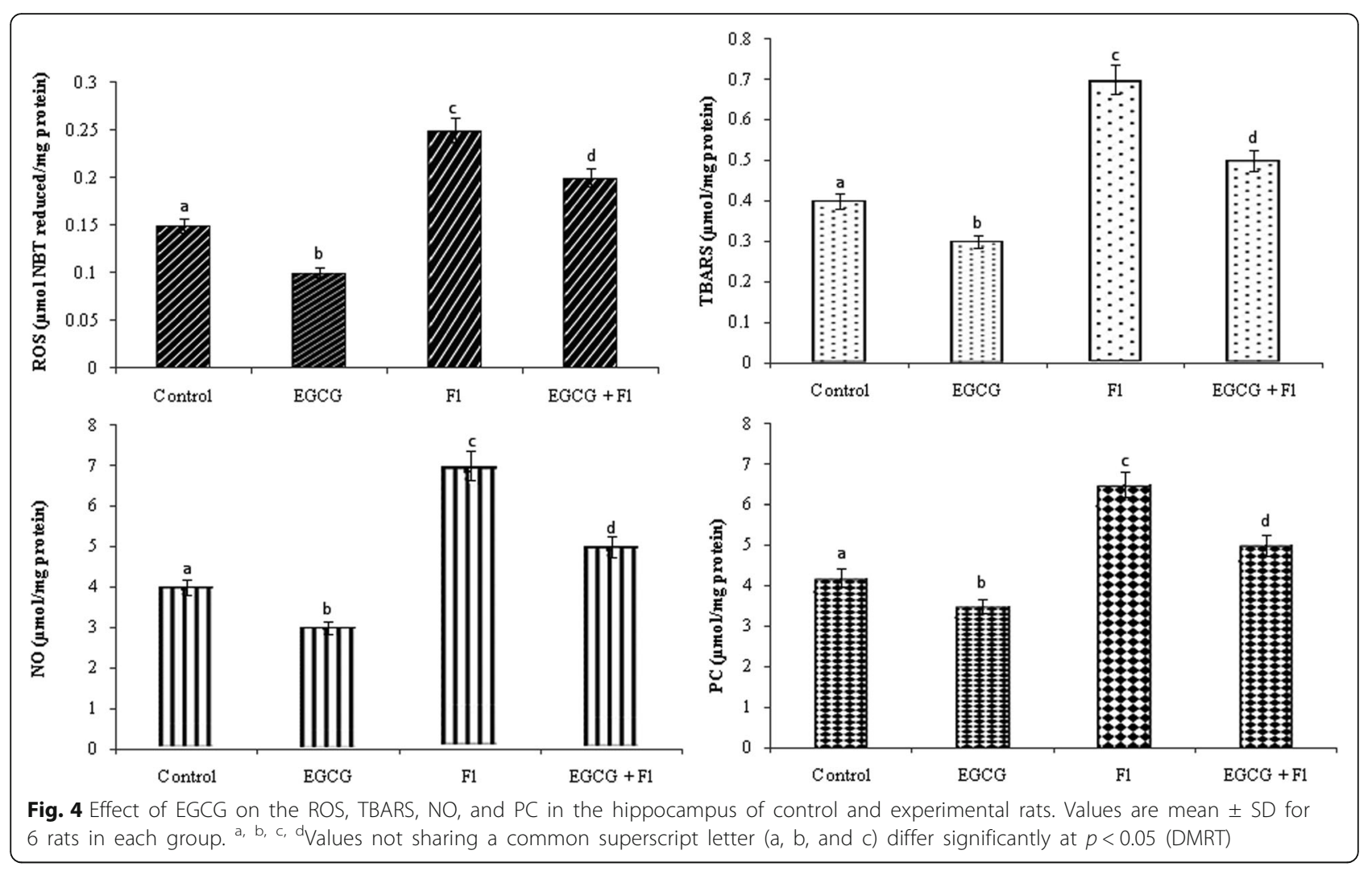

compared with control rats, whereas, pre administrated EGCG significantly $(p<0.05)$ retrieved the expressions of caspases to normal when compared with Fl-alone-treated rats. Thus, EGCG restrain apoptosis by inhibiting the expression of caspases.

\section{Effect of EGCG on Fl-induced DNA fragmentation}

Figure 12 shows the protective effect of EGCG on Flinduced DNA damage of control and experimental rats. Fl exposure exhibited a streak of fragmentation in the hippocampus (Lane 3) compared with control (Lane 1) and EGCG (Lane 2)-alone-treated animals. The pre-administration of EGCG along with Fl did not exhibit more fragmentation when compared with Fl-alone-treated rats (Lane 4). This indicated that $\mathrm{Fl}$ induces apoptosis and EGCG protects the DNA damage from oxidative stress by $\mathrm{Fl}$.

Effect of EGCG on Fl-induced caspase-3 immunoreactivity Light micrographs showed (Fig. 13) protective role of EGCG on Fl-induced caspase-3 immunohistochemistry of control and experimental rats. Moderate caspase-3 immunoreactivity was observed in the cytoplasm of neurons in control and EGCG rat (A and B). While the caspase-3 immunopositivity was increased in neurons of the hippocampus following $\mathrm{Fl}$ exposure (Fig.13c) when compared with control groups. However, pretreatment of EGCG (Fig. 13d) along with Fl markedly reduced the immunoreactivity of degenerating neurons after $\mathrm{Fl}$ exposure when compared with $\mathrm{Fl}$-alone-treated rats.

\section{Effect of EGCG on the hippocampus ultrastructure}

Figure 14 shows the protective effect of EGCG on Flinduced changes in the hippocampus by electron microscopic study of control and experimental rats. In the control and EGCG group, the ultrastructure of neurons in the hippocampus was normal (Fig. 14a, b). In the Fl-treated group, indicating the severe degenerative changes, shrunken cytoplasma (SC), slightly dilated cisternae (DC) of endoplasmic reticulum, and markedly swollen mitochondria (SM) with degenerated cristae were observed in neurons of the hippocampus. The nucleus of these cells seem to have increased evidence of nuclear membrane breakdown with chromatin disorganization and severely shrunken appearance of cell death (Fig. 14c). Pre-administration of EGCG was effective preventing the dilatation of endoplasmic reticulum, mitochondrial degeneration, 


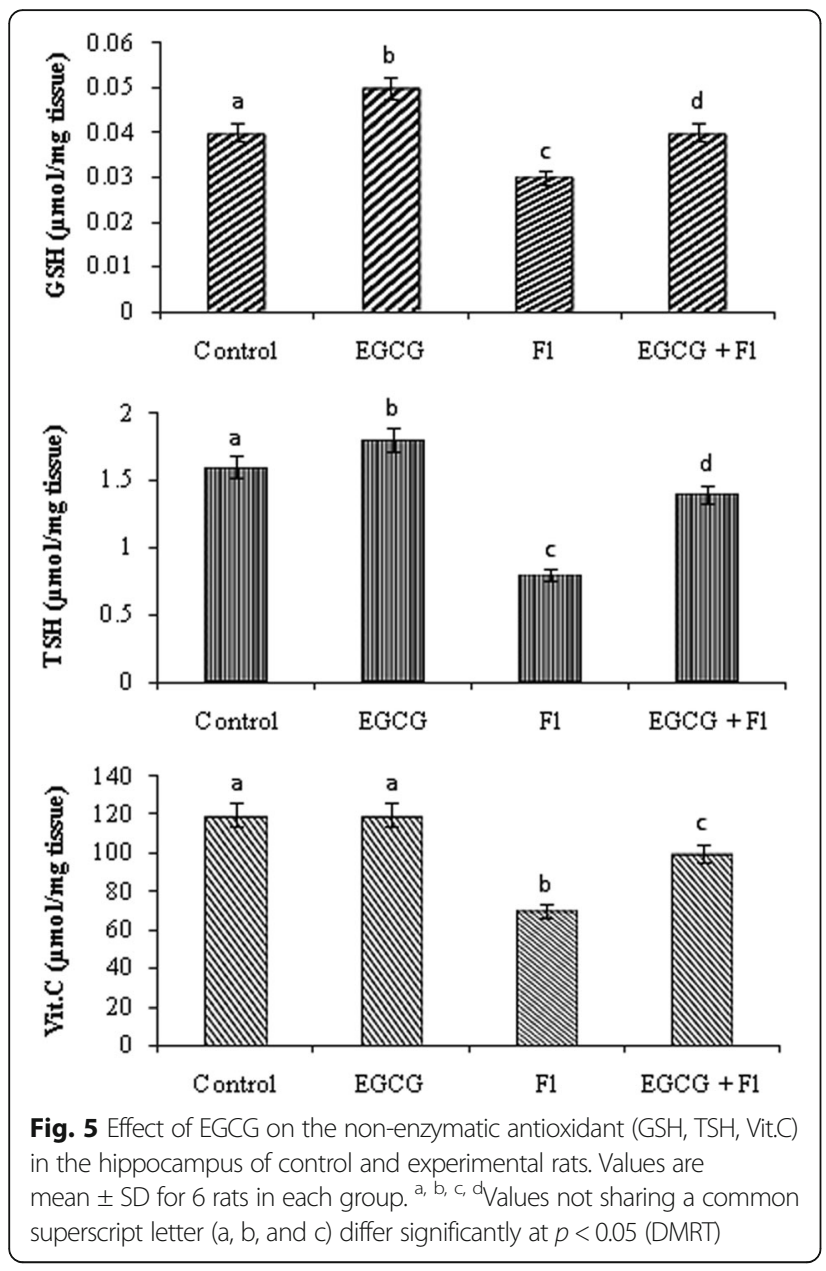

Table 4 Effect of EGCG on enzymatic antioxidants SOD, CAT, GPx, GST, GR, and G6PD in the hippocampus of control and experimental rats

\begin{tabular}{|c|c|c|c|c|}
\hline Groups & Control & EGCG & $\mathrm{Fl}$ & $\mathrm{EGCG}+\mathrm{FI}$ \\
\hline $\begin{array}{l}\text { SOD (min/mg } \\
\text { protein) }\end{array}$ & $12.40 \pm 0.37^{\mathrm{a}}$ & $13.89 \pm 0.29^{a}$ & $8.69 \pm 0.19^{b}$ & $10.23 \pm 0.18^{c}$ \\
\hline $\begin{array}{l}\text { CAT (min/mg } \\
\text { protein) }\end{array}$ & $68.30 \pm 7.09^{a}$ & $69.12 \pm 11.37^{\mathrm{a}}$ & $38.47 \pm 9.31^{b}$ & $54.25 \pm 10.09^{\circ}$ \\
\hline $\begin{array}{l}\text { GPx (min/mg } \\
\text { protein) }\end{array}$ & $11.39 \pm 0.45^{\mathrm{a}}$ & $12.96 \pm 0.84^{a}$ & $7.32 \pm 0.21^{b}$ & $10.71 \pm 0.43^{c}$ \\
\hline $\begin{array}{l}\text { GST (min/mg } \\
\text { protein) }\end{array}$ & $10.26 \pm 0.39^{a}$ & $10.60 \pm 0.57^{a}$ & $8.03 \pm 0.16^{b}$ & $10.42 \pm 0.37^{c}$ \\
\hline GR ( $\mu \mathrm{g} / \mathrm{mg}$ protein) & $30.73 \pm 6.89^{a}$ & $32.09 \pm 6.71^{\mathrm{a}}$ & $20.21 \pm 4.55^{b}$ & $27.38 \pm 0.71^{c}$ \\
\hline $\begin{array}{l}\text { G6PD ( } \mu \mathrm{g} / \mathrm{mg} \\
\text { protein) }\end{array}$ & $0.63 \pm 0.07^{\mathrm{a}}$ & $0.53 \pm 0.08^{b}$ & $0.48 \pm 0.06^{c}$ & $065 . \pm 0.09^{d}$ \\
\hline
\end{tabular}

Values are given as mean \pm SD from six rats in each group. ${ }^{a}$, b, cValues with different superscript letters $(a-c)$ in the same row differ significantly at $p<0.05$ (DMRT)

SOD-one unit of enzyme activity was taken as the enzyme reaction, which gave $50 \%$ inhibition of NBT reduction in $1 \mathrm{~min} / \mathrm{mg}$ protein. CAT $-\mu \mathrm{mol}$ of $\mathrm{H}_{2} \mathrm{O}_{2}$ utilized $/ \mathrm{min} / \mathrm{mg}$ protein. GPx- $\mu \mathrm{g}$ of $\mathrm{GSH}$ consumed $/ \mathrm{min} / \mathrm{mg}$ protein. GST— $\mu \mathrm{mol}$ of CDNB-GSH conjugate formed/min/mg protein. GR—nmol of $\mathrm{NADPH}$ oxidized $/ \mathrm{min} / \mathrm{mg}$ protein. G6PD were expressed as nmol of NADPH formed $/ \mathrm{min} / \mathrm{mg}$ protein

${ }^{a}$ Values do not differ significantly from control and EGCG group at $(p<0.05)$

${ }^{b}$ Values differ significantly from control and drug control group at $(p<0.05)$

c Values differ significantly from $\mathrm{Fl}$ group at $(p<0.05)$
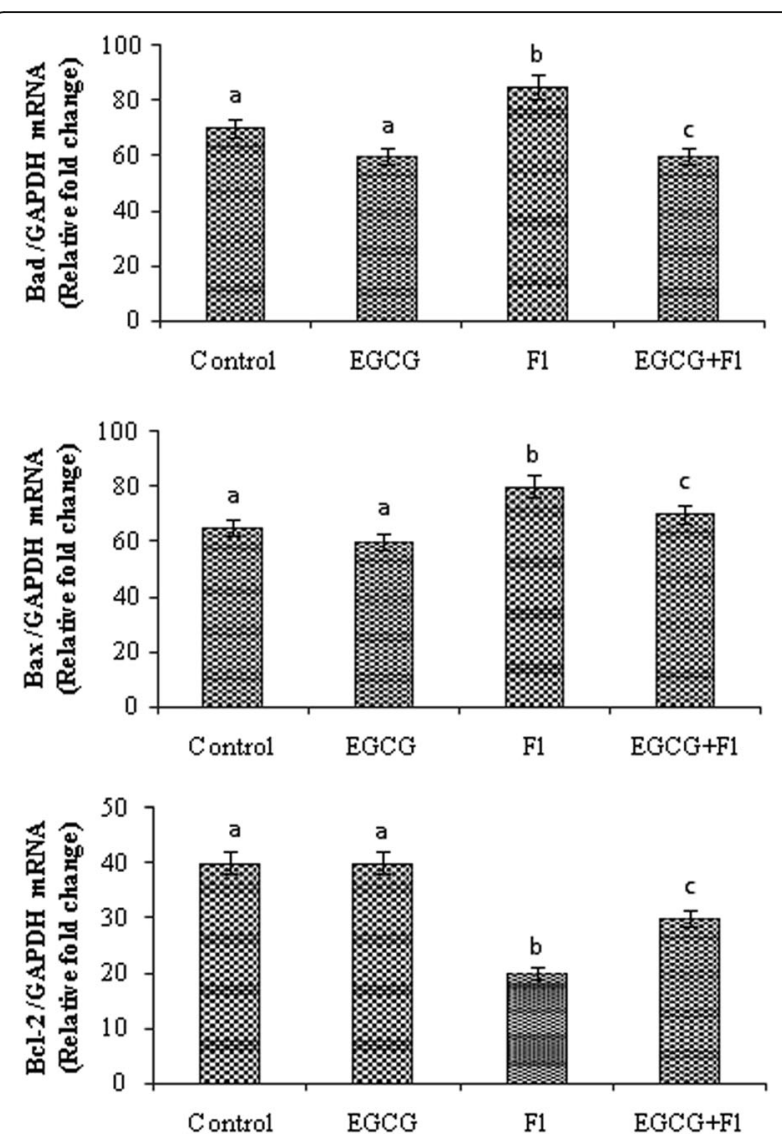

Fig. 6 Effect of EGCG on Bad, Bax, and Bcl2 mRNA expression in the hippocampus of control and experimental rats. Values are mean \pm SD for 6 rats in each group. ${ }^{a}$, b, 'Values not sharing a common superscript letter ( $a, b$, and c) differ significantly at $p<0.05$ (DMRT)

and irregularly shaped nuclei; the irregularly shaped chromatin clumps and moderately mitochondrial swollen were observed in neurons (Fig. 14d).

\section{Effect of EGCG on the hippocampus histology}

The protective role of EGCG on Fl-induced histological findings of control and an experimental rat was shown in Fig. 15. In the control and EGCG group, the morphology of neurons in the hippocampus was normal (Fig. 15a, b). In the Fl-treated group, the most consistent findings occurring in the histological tissue sections stained with hematoxylin-eosin were those indicating severe degenerative changes, shrunken cytoplasm, and extensively dark picnotic nuclei in the neurons of the hippocampus (Fig. 15c). Pre-administration of EGCG to Fl-treated rats significantly reduced all the neuronal changes into normal when compared with Fl-alonetreated rats (Fig. 15d). 


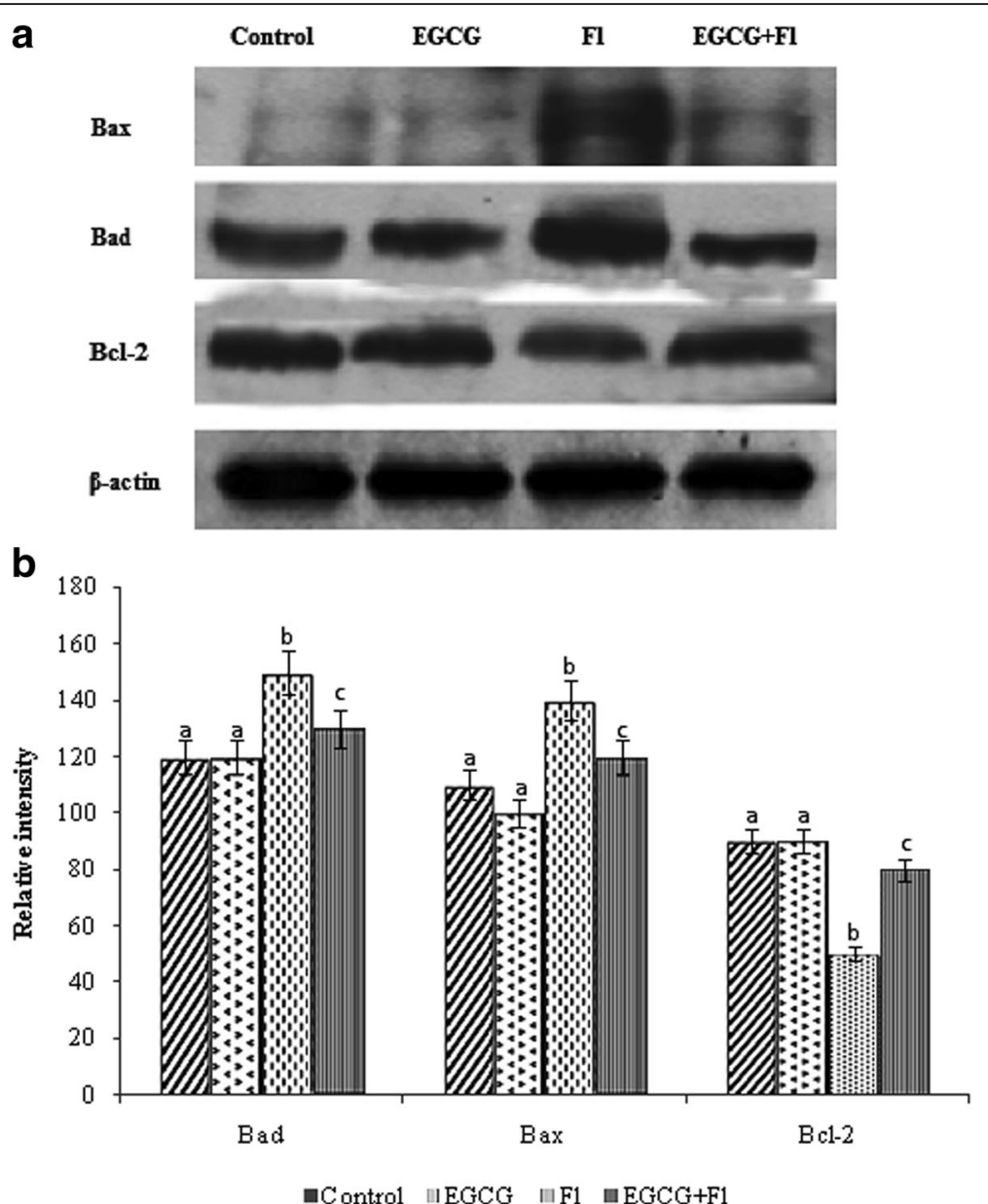

Fig. 7 a Effect of EGCG on Bad, Bax, and Bcl2 protein band intensity through western blot analysis in the hippocampus of control and experimental rats. $\mathbf{b}$ The densitometric analysis of protein expression of Bad, Bax and Bcl2 of hippocampus of control and experimental rats. Values are mean \pm SD for six rats in each group. ${ }^{a} b$ and c Values are not sharing a common superscript letter ( $a, b$ and $\left.c\right)$ differ significantly at $p<0.05$ (DMRT).

\section{Discussion}

The present study showed that $\mathrm{Fl}$ consumption induced significant changes in the antioxidant system and oxidative damage in the rat hippocampus. The administration of EGCG prior to Fl consumption modified the antioxidant response through mitigating the alterations in the analyzed biochemical parameters. Free radicals and other reactive substances play an important role in the progression or the initiation of some diseases such as neurodegenerative disorders. A correlation between $\mathrm{Fl}$ consumption and oxidative stress in rat neural tissues has been previously reported (Choi, Lee, Hong, \& Lee, 2012). In this context, the present study also confirmed that administration of EGCG significantly recovered the hippocampus function against $\mathrm{Fl}$ toxicity.

The symptoms of $\mathrm{Fl}$ toxicity in rats included decreased body weight and decreased water and food intake.
The alterations of the organ body weight ratio and absolute weight in Fl-intoxicated rats were due to tissue damage and a reduction in their functions. The results of the present study revealed a significant reduction in the food intake and body weight in Flintoxicated rats when compared with control rats; confirm this observation in line with the previous report of Miltonprabu and Thangapandiyan (2013). It is generally believed that the reduction in body weight is due to increased generation of reactive oxygen species (ROS) elicited by $\mathrm{Fl}$ as well as excessive breakdown of tissue proteins. Preadministered rats with EGCG significantly restored body weight, food intake, and relative organ weight compared with control. This is due to the ability of EGCG to mitigate the symptoms of Fl-induced neuronal toxicity by its potent antioxidant and antiradical activity as it was previously reported by Kumar and Kumar (2009). 


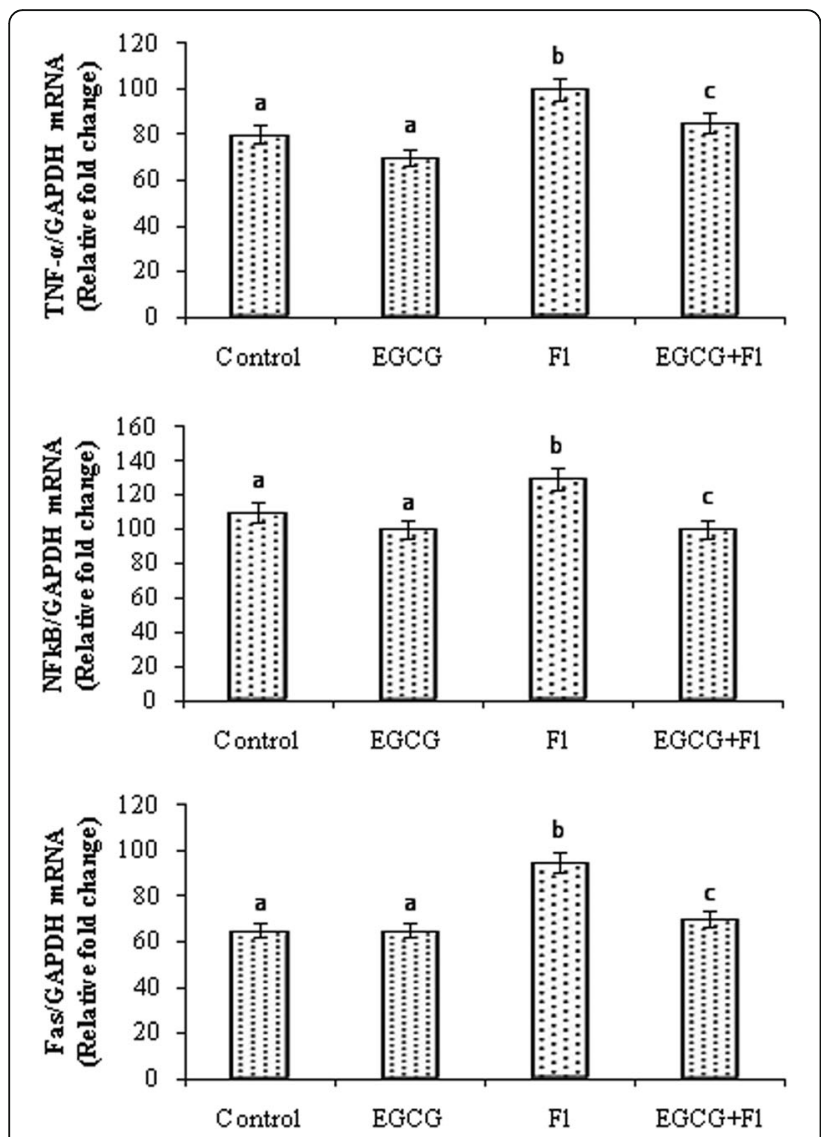

Fig. 8 Effect of EGCG on TNF-a, NF-kB, and Fas mRNA expression in the hippocampus of control and experimental rats. Values are mean \pm SD for 6 rats in each group. ${ }^{a}, b$, ${ }^{c}$ alues not sharing a common superscript letter (a, b, and c) differ significantly at $p<0.05$ (DMRT)

Neurotransmitters are endogenous chemicals that transmit signals across a synapse from one neuron cell to another target neuron. Fl has been well documented for its neurotoxic effect mediated through the generation of ROS in cells (Russell, 2004). In the present study, neurotransmitters such as AchE (acetylecholinesterase), norepinephrin (NP), dopamine (DA), and 5-hydroxytriptamin (5-HT) were significantly decreased in fluoride-intoxicated rats. Our findings is well corroborated with the previous reports of Flora, Mittal, and Mishra (2009) in Fl-intoxicated rats. This may be due to the over production of free radicals mediated lipid peroxidation in brain which will affect the synthesis of neurotransmitters. Moreover, the decreased levels of NE and DP due to the decreased activity of enzymes involved in their synthesis like tyrosine hydroxylase, DOPA decarboxylase and dopamine $\beta$-hydroxylase or to the enhanced release of catechol-O-methyl transferase caused by increased
ROS-mediated lipidperoxidation and nitric oxide activity by Fl (Flora et al., 2009). Similarly, a significant decreased activity of AChE in Fl-exposed animals was reported by Long et al. (2002) in rats. Preadministration of EGCG significantly improved the altered neurotransmitters in the brain of Fl-intoxicated rats via its enhanced ROS scavenging ability as reported by Kumar and Kumar (2009). Further, the dominant hydrogen-donating activity of EGCG activates the Nrf2 proteins and increase the phase II antioxidants, thereby preventing the Fl-induced generation of ROS/RNS in the rat brain. Moreover, EGCG has been proved to be a potent antioxidant which inhibited the Fl-mediated Keap 1 proteins and DNA damage; lipid peroxidation in the brain, liver, and kidney of rats; and increased the activity of antioxidant enzymes, such as glutathione peroxidase (GPx), glutathione reductase (GR), superoxide dismutase (SOD), and catalase (CAT) in rats (Kumar \& Kumar, 2009; Thangapandiyan \& Miltonprabu, 2013; Thangapandiyan \& Miltonprabu, 2014).

The neurodegenaration can occur when $\mathrm{Fl}$ penetrates the brain through the blood stream. In fatal stage, Fl concentration or accumulation leads to alternation in growth, cell differentiation, and sub cellular organization in brain cells (Madhusudhan et al., 2009). In the present study, we observed a significant increase in the concentration of $\mathrm{Fl}$ elements in the Fl-intoxicated rat hippocampus which was similar with the previous report of Pratap Reddy, Sailaja, and Krishnaiah (2009). This may be due to the diminished levels $\mathrm{AChE}$ in the of Flintoxicated rats, which could further lead to accumulation of $\mathrm{Fl}$ ions and disturb the neurotransmitters through its electronegative property. Pre-treatments of EGCG to Fl-intoxicated rats showed a significant reduction in the level of $\mathrm{Fl}$ concentration and elevate the AChE activity in the brain. This may be due to the strong antioxidant property of EGCG (gallate moiety esterified at the 3rd position of the $C$ ring) coupled with the highly electronegative $\mathrm{Fl}$ ions towards hydrogen groups resulting in lesser bioavailability of toxic $\mathrm{Fl}$ ions in the brain.

In our study, we observed a significant increase in the level of ROS, TBARS, NO, and PC production due to continuous ROS production by $\mathrm{Fl}$. This result was corroborating with the previous report of Nabavi et al. (2012) who reported that the ROS production by Fl has frequently been attributed to block mitochondrial respiratory chain complex I, thereby increasing the formation of these oxidative stress markers. Fl blocks electron flow through the respiratory chain complex I, followed by enhancement of $\mathrm{O}_{2}^{-}$formation (Bera et al., 2007). This appears to be the primary mechanism of Fl-induced formation of $\mathrm{O}_{2}^{-}$, which can rapidly evolve from $\mathrm{H}_{2} \mathrm{O}_{2}$ in the hippocampus, thereby increasing the ROS, lipid 


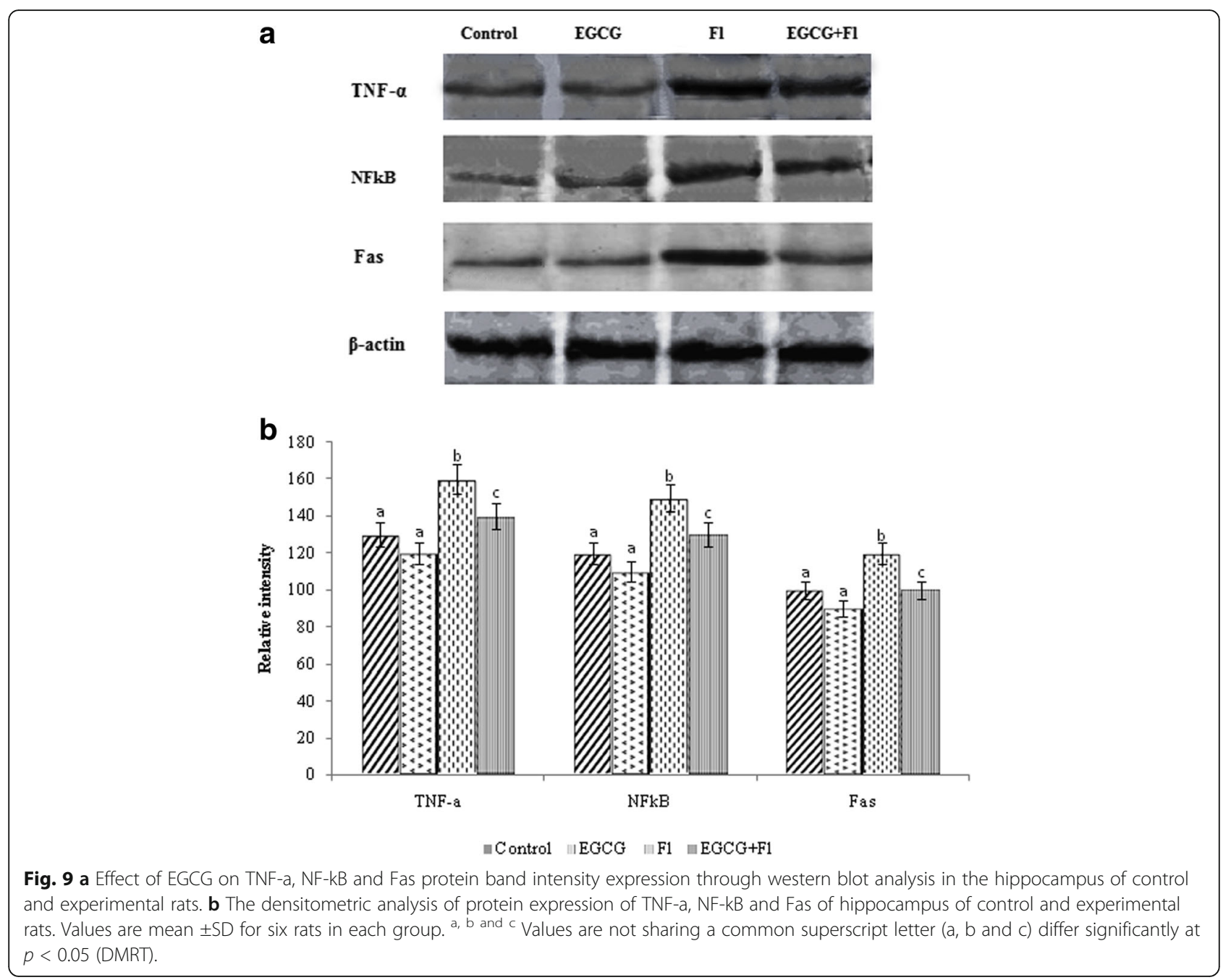

peroxidation, and oxidize membrane proteins. The elevation of $\mathrm{NO}$ production in the Fl-intoxicated rats may inhibit key enzymes of energy metabolism and damage DNA, that deplete intracellular glutathione and react with superoxide to form the much more powerful oxidant peroxynitrite $\left(\mathrm{ONOO}^{-}\right)$(Bolanos et al., 1997). In the current study, pre-administration with EGCG to Flintoxicated rats showed a significant decrease in these altered biochemical parameters in to near normal. This might be neuroprotective effects of EGCG in variety of animal models by inhibition of enhanced oxidativenitrosative stress and augmentation of antioxidant defense ability (Kim, Lee, Park, \& Jang, 2009).

Antioxidant enzymes are considered to be the first line of cellular defense against oxidative damage. SOD is an antioxidant (metallo enzyme) that reduces superoxide radicals into less hydrogen peroxide molecule (McCord, Keele, \& Fridovich, 1976). CAT is a hemeprotein, which reduces hydrogen peroxide into molecular oxygen and water (Gutteridge, 1995). Reduction in SOD activity in the brain tissue of Fl-exposed animals may be due to the enhanced production of super oxide radical anions (Nabavi et al., 2011). Fl intoxication also significantly reduced the CAT activity in the hippocampus of rats due to inhibition of NADH. The paucity of NADH accumulation during $\mathrm{Fl}$ metabolism might decrease the catalase activity. NADH is required for the activation of CAT from its inactive form. GST and GPx are two antioxidant enzymes, which counteract free radical generation. GST and GPx play principle roles in the reduction of organic hydroperoxides within membranes and lipoproteins in the presence of GSH. Decrease in GSH content and increase from the level of lipid peroxidation due to $\mathrm{Fl}$ toxicity simultaneously decreased the activities of GST and GPx with a concomitant decrease in the activity of GSH-regenerating enzyme, glutathione reductase (GR). G6PD is an important enzyme of hexosemonophosphate (HMP) shunt. 


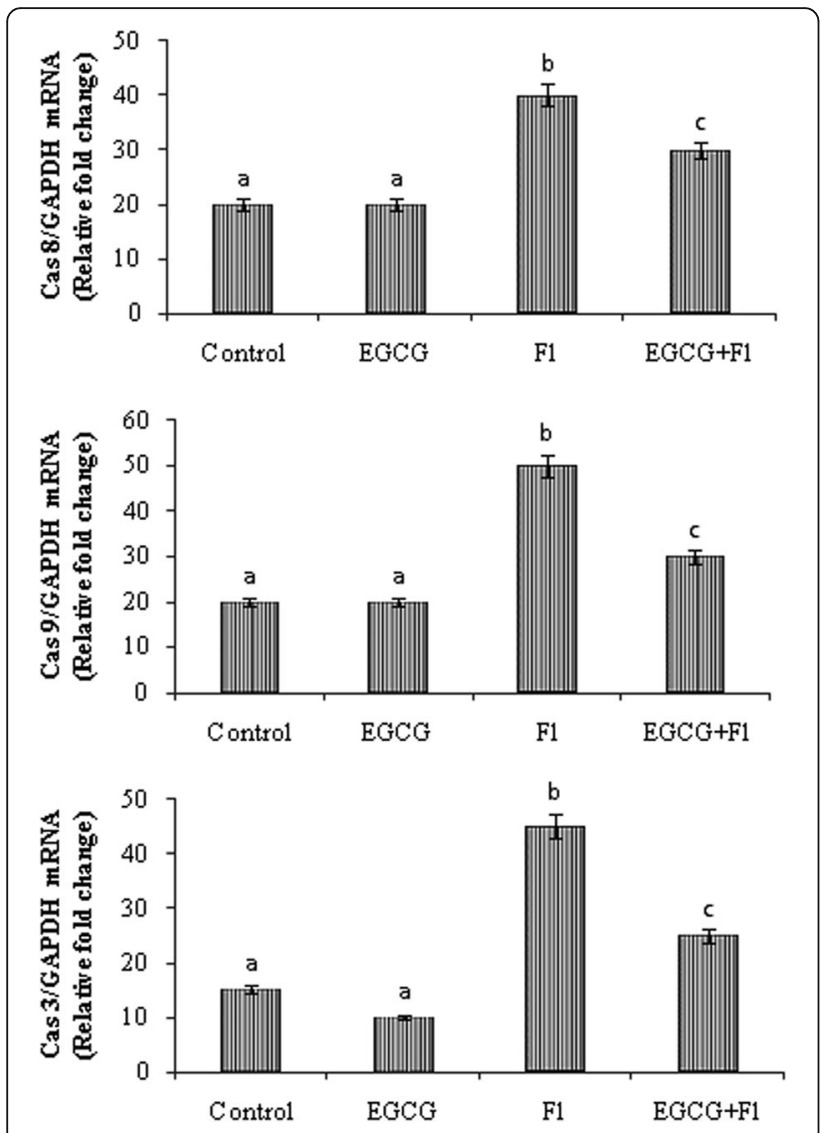

Fig. 10 Effect of EGCG on Caspases 8, 9, and 3 mRNA expression in the hippocampus of control and experimental rats. Values are mean \pm SD for 6 rats in each group. ${ }^{a, b}$, c Values not sharing a common superscript letter ( $a, b$, and c) differ significantly at $p<0.05(\mathrm{DMRT})$

It converts one molecule of glucose-6-phosphate into 6-phosphogluconolactone in the presence of $\mathrm{Mg}^{2+}$, $\mathrm{Mn}^{2+}$, and $\mathrm{Ca}^{2+}$ ions, and subsequently, $\mathrm{NADP}^{+}$is reduced to NADPH. A subsequent reduction of the G6PD activity in Fl-intoxicated rats showed impaired generation of NADPH which is required for the reduction of GSSG to GSH (Thangapandiyan \& Miltonprabu, 2013). Pre-treatment with EGCG prior to $\mathrm{Fl}$ intoxication prevented the alterations in the activities of SOD, CAT, GST, GPx, GR, and G6PD in the hippocampus probably by free radical scavenging properties through its gallate moiety esterified at the 3rd position of the $C$ ring, the catechol group (3, 4, 5-trihydroxyl groups) on the $\mathrm{B}$ ring and the hydroxyl groups at the 5th and 7th positions on the A ring (Cabrera, Artacho, \& Gimenez, 2006).

Non-enzymatic antioxidants contribute the subsequent line of cellular defense against Fl-induced oxidative damage. In our study, we found a significant decrease in the level of $\mathrm{GSH}$ due to oxidation of $-\mathrm{SH}$ group by Fl-induced ROS and thereby inhibiting GSH, and TSH level in the hippocampus which are in coincide with the report of Nabavi et al. (2012) in Flintoxicated rats. Decreased level of vitamin $\mathrm{C}$ could be due to increased utilization of vitamin $\mathrm{C}$ against amplified ROS or could be due to decrease in GSH level in the hippocampus (Jones, 2002). Treatment of EGCG prior to Fl-intoxicated rats significantly increased the non-enzymatic antioxidant markers such as GSH, TSH, and $\mathrm{Vit} \mathrm{C}$ in the hippocampus by its strong free radical scavenging activity.

Bcl-2 family proteins are the key regulators of physiological and pathological apoptosis. The family consists of both cell death promoters such as Bax, Bad and cell death inhibitors Bcl-2, Bcl-xl, etc. It has been demonstrated that the high ratio of $\mathrm{Bax} / \mathrm{Bcl}-2$ is associated with greater vulnerability for the activation apoptosis by $\mathrm{Fl}$ (Lee et al., 2008). The balance between the up- and downregulations of the members of pro-apoptotic (Bax, $\mathrm{Bad}$ ) and anti-apoptotic (Bcl-2) family protein determines the fate of the cells either to undergo apoptosis or to survive in pathophysiology. In the present study, we observed a significant increase in the levels of proapoptotic markers (Bax and Bad) with a significant decrease anti-apoptotic marker (Bcl-2) in the Fl-intoxicated rats as evidenced from the RT-PCR (Fig. 6) and western blotting (Fig. 7) analysis. This is due to the exceeded ROS by $\mathrm{Fl}$ through intrinsic pathway, which involves the release of cytochrome $\mathrm{C}$ from the mitochondria which was upregulated pro-apoptotic proteins against antiapoptotic proteins in the hippocampus of rats. However, pre-administration of EGCG to Fl-intoxicated rats significantly improved the altered apoptotic proteins into normal when compared with control. This may be due to the inhibition of pro-apoptotic mediated intrinsic pathway by EGCG via its strong antioxidant action as well as influence of the phase II antioxidant through $\mathrm{Nrf} 2$ activation in nucleous ( $\mathrm{Na} \&$ Surh, 2008).

Death receptors are cell surface receptors that transmit apoptotic signals initiated by specific ligands such as Fas ligand, TNF alpha, and TNF-related apoptosis inducing ligand (TRAIL) which finally activate caspases cascade (Locksley, Killeen, \& Lenardo, 2001). The upregulation of TNF- $\alpha$ by Fl-induced oxidative stress results from Fas-mediated induction to apoptosis. In the present study, we observed that TNF- $\alpha$ mRNA (Fig. 8) and protein (Fig. 9) were significantly increased after $\mathrm{Fl}$ exposure in the hippocampus. The binding of TNF- $\alpha$ to TNFR 1 results in captor trimerisation and clustering of intra cellular death domains. This will activate caspase- 8 that demonstrates the TNF receptor signaling pathway evidenced by increased caspase- 8 mRNA expression (Fig. 10) in the 


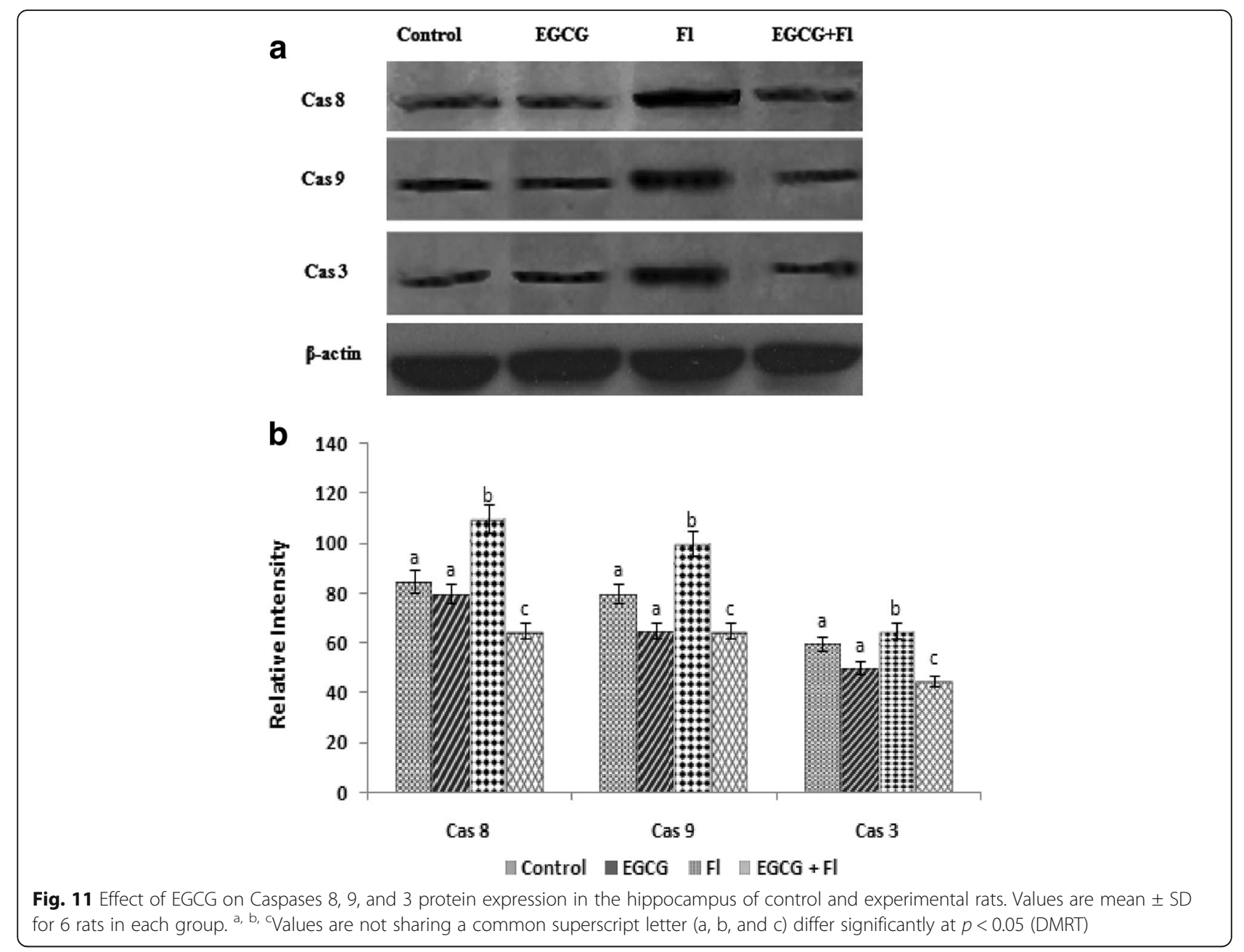

hippocampus of adult rats. The ligations of Fas stimulate NF-kB activation (Hofmann, Schiekofer, \& Isermann, 1999). NF-kB is a complex protein and is found to be constitutively expressed in mammalian cells. In normal cells, NF-kB dimers are sequestered in the cytoplasm by inhibitory Kappa B (IkB). When it is exposed to external signal degradation of $\mathrm{IkB}$, free NF-kB translocation into the nucleus. But the present study, on hippocampal neurons, revealed a significant increase in mRNA and protein were observed in Flintoxicated rats which are in agreement with the previous report of Hofmann et al. (1999).

In the present study, induction of TNF- $\alpha$ and NF-kB, after $\mathrm{Fl}$ exposure, plays a critical role on hippocampal neurodegeneration. The Fas-activating death receptor pathway is critical for hippocampal apoptosis, which is easily activated by oxidative stress (Selvakumar et al., 2012). Fas is a type I membrane protein belonging to the tumor necrosis factor receptor family. The combination of Fas and FasL leads to the multimerization of Fas which Fas-associated protein with death domain (FADD) via interactions between the death domain of Fas and FADD (Salvesen \& Riedl, 2009). Subsequently, procaspase- 8 binds to Fas-bound FADD via interactions between the death effector domains of FADD and procaspase-8, leading to the activation of cas- 8 and cas-9 (Strasser, Jost, \& Nagata, 2009), which in turn activates caspase-3, then leading cell to apoptosis (Tsuruta, Oh-hashi, Kiuchi, \& Hirata, 2008). In this study, we demonstrated that the pretreatment with EGCG significantly decreased apoptosis expression in the hippocampus of Fl-intoxicated rats compared to control rats. Caspases are mediators of apoptosis; decreased apoptosis is the result of EGCG pre-treatment in Fl-intoxicated rats. This finding indicates that EGCG exposure inhibits both intrinsic and extrinsic pathway of $\mathrm{Fl}$ in the hippocampus of the rat brain via its various pharmacological properties such as antioxidant, antimutagenic, and neuroprotective nature of EGCG (Lee et al., 2000). 


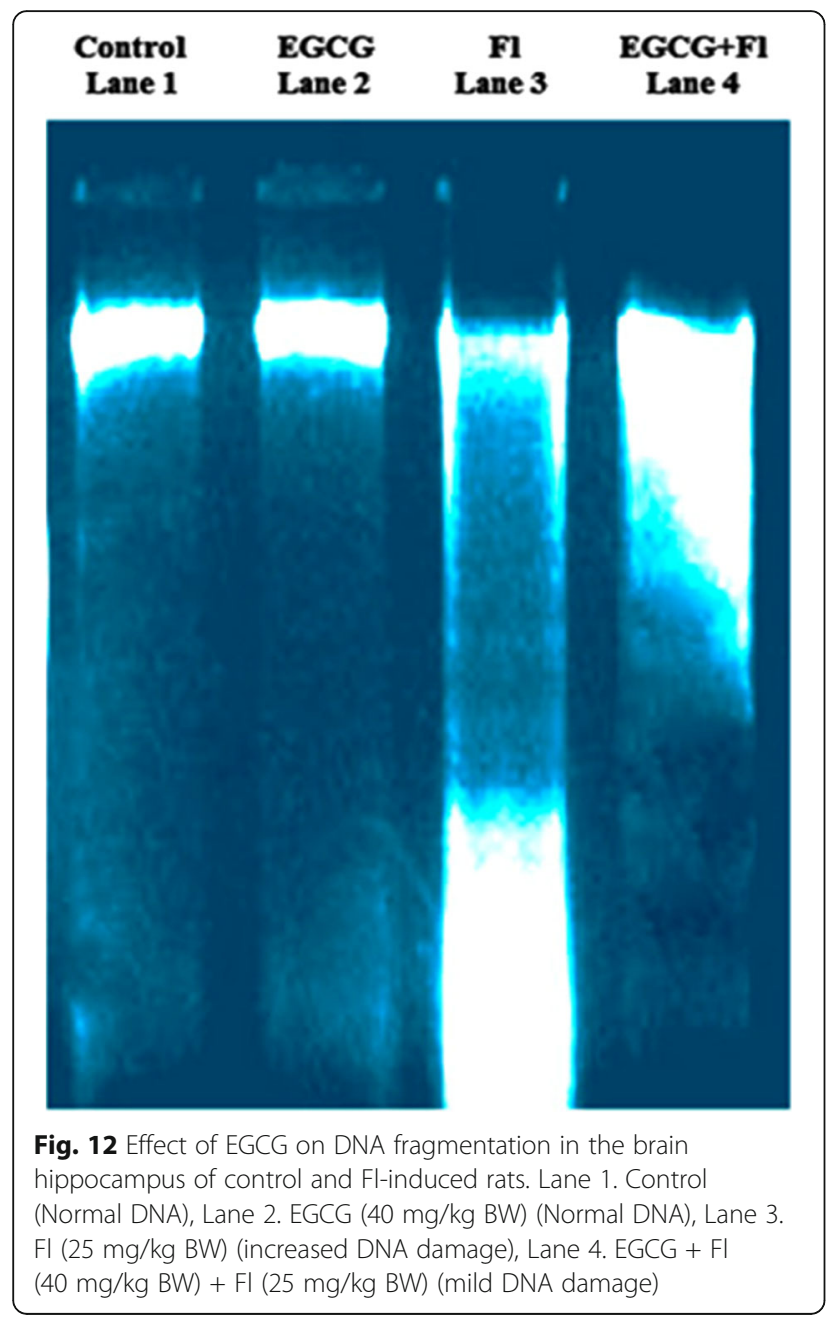

$\mathrm{Fl}$ is a dense negatively charged ion biochemically very active and thus directly affects DNA because of its strong affinity for uracil and amide bonds by the interaction with $-\mathrm{NH}(\mathrm{Li}$, Heerema, \& Dunipace, 1987). Fl can induce the production of free radicals, which can damage DNA strands directly or indirectly by lipid peroxidation. Fl-induced free radicals depress the DNA polymerase activity, which might further affect the process of DNA replication or repair mechanism (Aardema \& Tsutsui, 1995). EGCG has been reported to be effective in prevention of oxidative damage to DNA (Anderson et al., 2001). The antioxidant property of EGCG is mainly dependent on its scavenging properties of $\mathrm{O}_{2}$-- and $\mathrm{HO}^{-}$. In the present study, we explored that significant increase in DNA damage was observed in Fl-intoxicated rats. This may be due to the strong affinity with uracil and amide bonds by $\mathrm{Fl}$ and interact with $-\mathrm{NH}$ group and thereby damage the DNA. EGCG preadministration to Fl-intoxicated rats showed that a significant decrease in DNA damage were observed, well corroborating with the earlier report of Anderson et al. (2001) who explored EGCG is a potent antioxidant agent for DNA damage.

Although several studies have been examined about Fl-induced ROS effects on various brain regions, we have demonstrated the expression of caspases-3 activity on the rat hippocampus by immunohistochemistry. In the present study, a significant increase in the levels of caspases-3 was observed in Fl-intoxicated rats as evidenced by disarrangement of neuronal cells with contrast staining when compared to control. This may be due to the Fl-induced ROS accumulation in the hippocampus via TNF- $\alpha$-mediated apoptotic pathway that activate the release of caspases-3 from mitochondria. Pre-administration of EGCG significantly decreased the activity of caspases- 3 and renovate its normal neurons as evidenced by weak staining.

Histological observations of the brain hippocampus revealed that $\mathrm{Fl}$ intoxication caused abnormal structural changes in the hippocampus tissue including necrosis, nuclear vacuolization, pycnosis, and inflammatory changes. Regarding the histological observation, no significant difference was observed between control and EGCG-treated groups. Pre-administration of EGCG to Fl-intoxicated rats observed a significant neuroprotective efficacy, preventing the neuronal damage on Fl-induced hippocampal.

Transmission electron microscopic study of the control and EGCG-treated rats showed normal mitochondria, nucleolus with usual architecture. The TEM images of Fl-intoxicated rats showed shrunken cytoplasm, swelling of mitochondria, fragmented nucleolus with degenerated cristae, and nuclear membrane breakdown with chromatin disorganization in the neurons of the hippocampus. These ultrastructural abnormalities of neurons clearly illustrated the neurotoxic action of Fl. The swelling of mitochondria that have been subjected to oxidative stress conditions, which could be due to the accumulation of lipid peroxide products as a result of glutathione depletion, leads to membrane damage. Pre-administration of EGCG to Fl-intoxicated rats showed a considerable recovery of hippocampal neurons with no swelling of nucleolus and mitochondria.

\section{Conclusions}

In conclusion, the current data supports that EGCG acts as a potential defending agent, which might prevent the Fl-induced oxidative neurotoxicity by decreasing lipid peroxidation, protein oxidation, and DNA damage, and enhance the enzymatic and nonenzymatic antioxidant status via Nrf2 in the hippocampus. The present investigation also provides a well- 


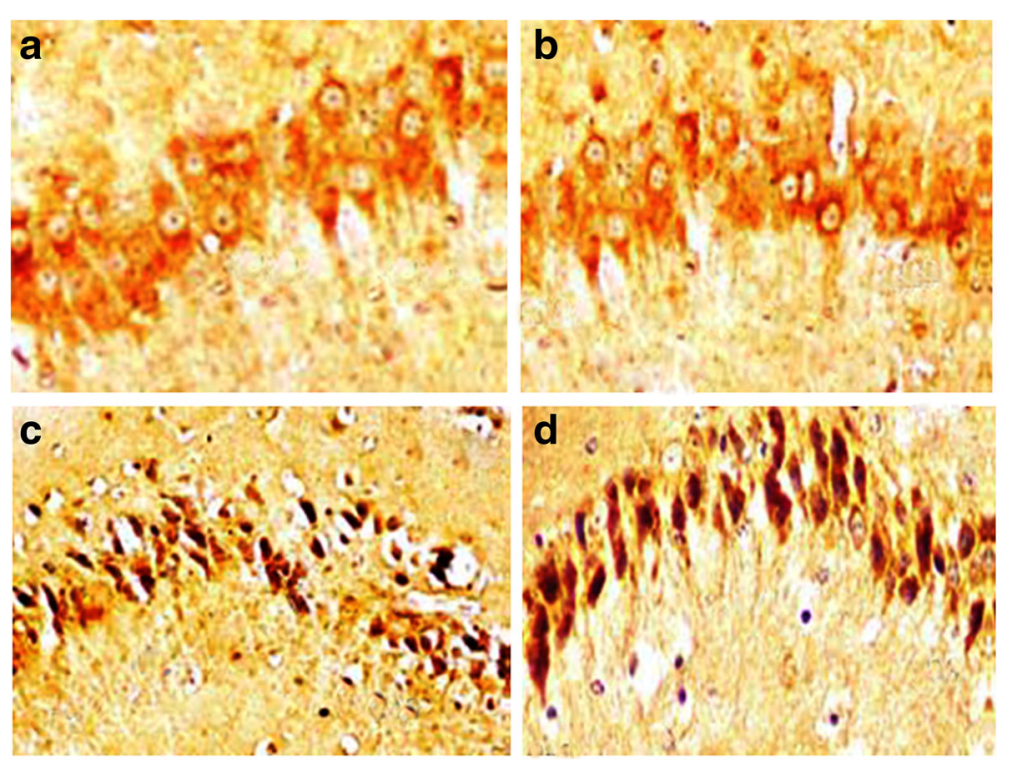

Fig. 13 Effect of EGCG on the hippocampus after Fl exposure by Caspase-3 immunohistochemistry in the control and experimental rats. a Control rats: neuronal cells are moderately stained with the anti-caspase-3 antibody. $\mathbf{b}$ EGCG-treated rats also showed similar to that of control neuronal cells appearance. $\mathbf{c}$ Fl-treated rats shows the strong immunopositivity caspases-3 in the hippocampus. $\mathbf{d}$ Fl-treated rats pre-treated with EGCG shows markedly reduced immunoreactivity of degeneration of neuron after $\mathrm{Fl}$ exposure in the hippocampus
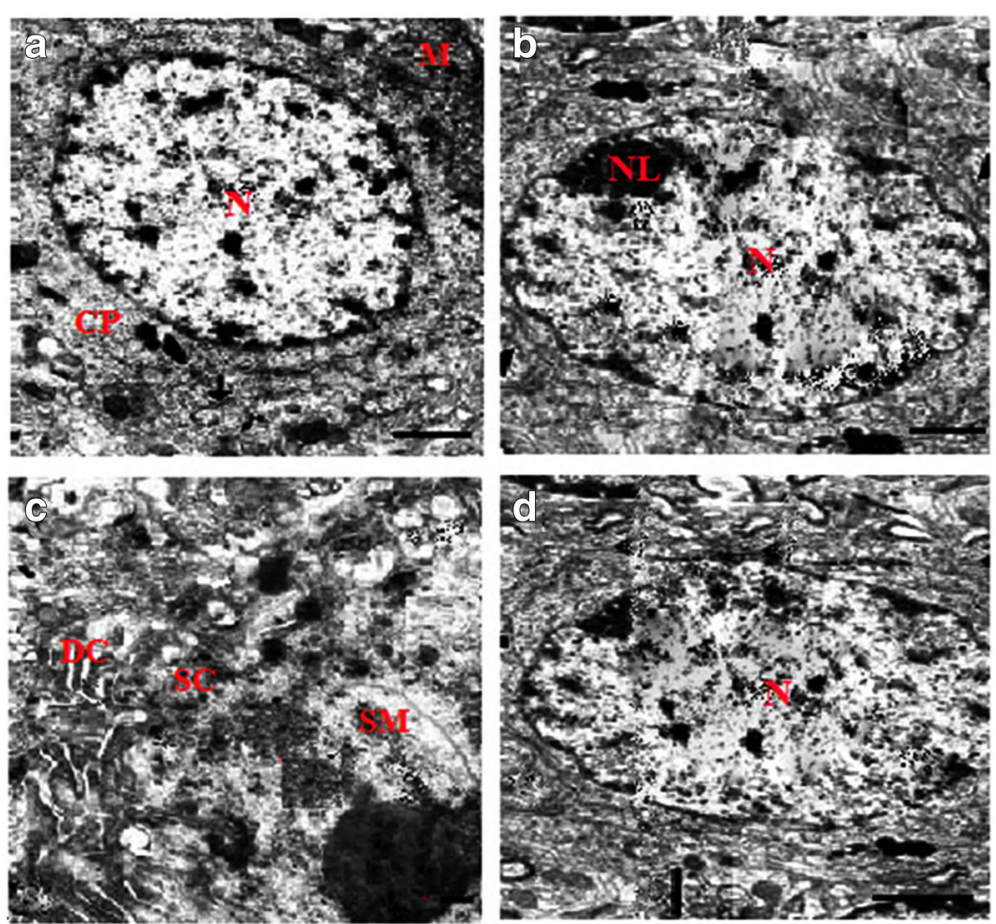

Fig. 14 Effect of EGCG on Fl induced ultra changes in the hippocampus by transmission of electron microphotographs in the hippocampus of control and experimental animals (a-d). a Control rats: normal neurons are shown condensed, regularly shaped, round nucleous $(\mathrm{N})$ and nucleoulus (NL) in normal cells. b EGCG-treated rats: the ultrastructure of cytoplasm (CP) and cytoplasmic organelles showed a normal appearance of nucleous (N), mitochondria (M), and nucleoulus (NL). c Fl-treated rats: disintegrating neuron containing shrunken cytoplasm (SC), slightly dilated cisternae (DC) of endoplasmic reticulum and swollen mitochondria (SM) were observed. Typical necrotic neurons had smaller clumps of irregularly shaped, condensed chromatin with nuclear membrane breakdown. $\mathbf{d}$ Fl-treated rats with EGCG: EGCG treatment was effectively preventing the abovementioned findings, compared to control (NL: nucleolus, N: nucleus, CP: cytoplasm, DC: dilated cisternae SC: shrunken cytoplasm, SM: swollen mitochondria (scale bars, $1 \mu \mathrm{m}$ ) 


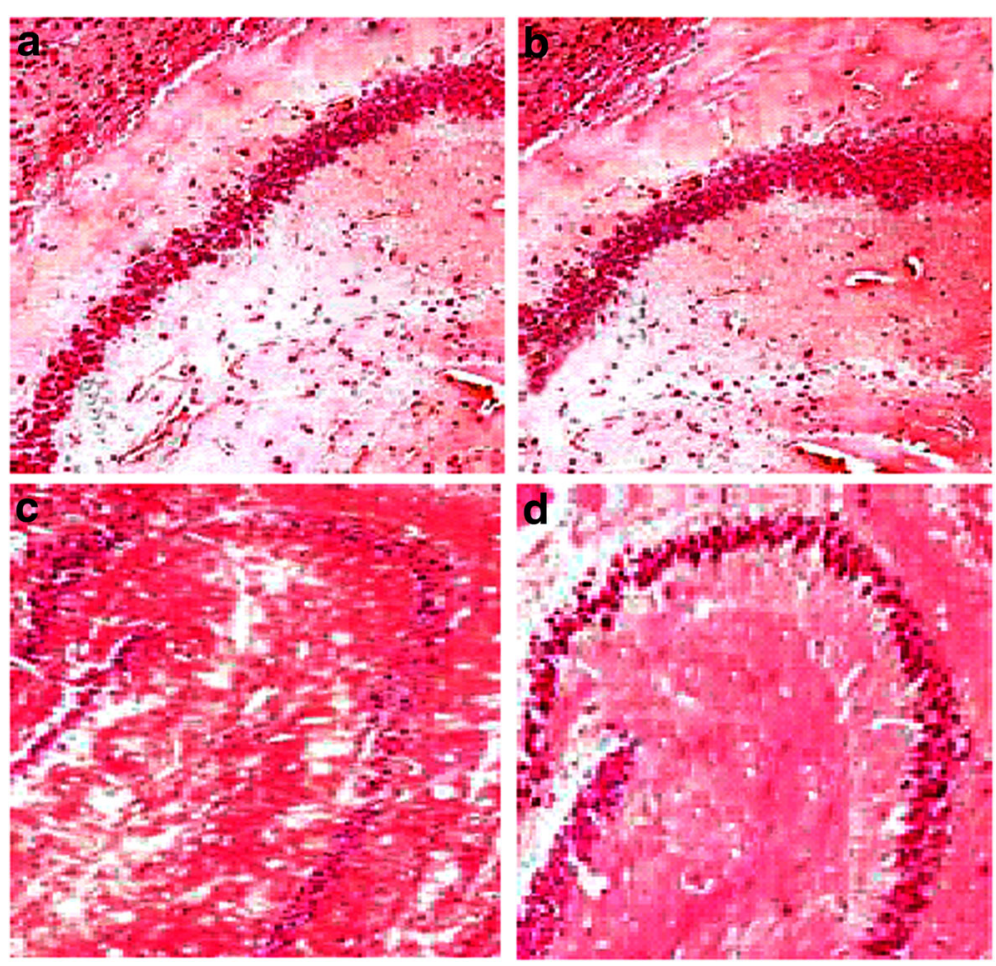

Fig. 15 Effect of EGCG on the Fl-induced changes in the histology of neurons in the hippocampus of control and Fl exposure (a-d). a Control rats: normal hippocampal tissue histology is seen $(\times 40)$. $\mathbf{b}$ EGCG rats: although similar hippocampal tissue histology was observed compared to control ( $\times 40)$. c Fl-treated rats: increased degenerative changes, shrinkage cytoplasm, and extensively dark picnotic nuclei in neurons of the hippocampus are seen $(\times 40)$. d Fl-treated rats with EGCG: effective preventing of degenerative changes and shrunken in cytoplasm and nuclei are prominent in neuronal cells. $(H \& E \times 40)$

validated supportive literature about counteracting the Fl toxicity with EGCG in fluoride prone zone. However, further investigations are warranted to elucidate the precise molecular mechanism of EGCG against Fl-induced toxicity in humans.

\section{Abbreviation}

5-HT: 5-Hydroxytrophoamin; AChE: Acetilecholine esterase; Bad: BCl-2associated death promoter; Bax: Bcl-2-associated X protein; BCl-2: B-cell lymphoma 2; Cas-3: Caspase-3; Cas-9: Caspase-9; CAT: Catalase;

CD: Conjugated dienes; Cyt-C: Cytochrome C; DA: Dopamine; DMRT: Duncan multiple ranges test; EGCG: Epigallocatechin gallate; Fl: Fluoride;

G6PD: Glucose 6-phosphate dehydrogenase; GPx: Glutathione peroxidase; GR: Glutathione reductase; GSH: Reduced glutathione; GSSG: Oxidized glutathione; GST: Glutathione-S-transferase; H\&E: Hematoxylin and eosin; HO-1: Heme oxygenase-1; iNOS: Inducible Nitric Oxide Synthetase; Keap-1: Kelch-like ECH-associated protein 1; LOOH: Lipid hydroperoxides; NF-kB: Nuclear Factor-KappaB; NP: Norepinephrine; Nrf-2: Nuclear-related factor-2; PC: Protein carbonyl contents; ROS: Reactive oxygen species; SOD: Superoxide dismutase; TBARS: Thiobarbituric Acid Reactive Substances; TEM: Transmission electron microscope; TSH: Total sulphydryl groups

\section{Acknowledgements}

The authors acknowledge the Professor and Head of the Department of Zoology, Annamalai University and Bharathiyar university for their geneorous support in this study.

\section{Funding}

This study was supported by University Grant Commission for staff assisted programme (UGC-SAP) for their generous support.

\section{Availability of data and materials}

Not applicable.

\section{Authors' contributions}

Conceived and designed the experiments: ST and SM, Performed the experiments and Analyzed the data: ST and V. Contributed reagents/ materials/analysis tools: T, S and V. Wrote the paper: ST, SM and MR. All authors read and approved the final manuscript.

\section{Ethics approval}

All animals (rats) received human care according to the criteria outlined in the Guide for the care and use of Laboratory Animals. Animal handling and experimental procedures were approved by the Institutional Animal Ethics Committee (Registration Number: 952/2012/CPCSEA), Annamalai University, Annamalai nagar, India.

\section{Competing interests}

The authors declare that they have no competing interests.

\section{Publisher's Note}

Springer Nature remains neutral with regard to jurisdictional claims in published maps and institutional affiliations.

\section{Author details}

'Department of Zoology, Annamalai University, Annamalai Nagar 608002, Chidambaram, India. 'Department of Zoology, Bharathiar University, Coimbatore, India. 
Received: 1 June 2017 Accepted: 5 January 2018

Published online: 27 February 2018

\section{References}

Aardema MJ, Tsutsui, T., 1995. Sodium Fl induced chromosome aberrations in different cell cycle stages. Mutation Research, 331, 171-2

Anderson, R. F., Fisher, L. J., Hara, Y., Harris, T., Mak, W. B., \& Melton, L. D. (2001). Green tea catechins partially protect DNA from (-) OH radical induced strand breaks and base damage through fast chemical repair of DNA radicals. Carcinogenesis, 22, 1189-1193.

Anuradha, C. D., Kanno, S., \& Hirano, S. (2001). Oxidative damage to mitochondria is a preliminary step to caspase-3 activation in Fl-induced apoptosis in HL60 cells. Free Radical Biology and Medicine, 31, 367-373.

Bera, I., Sabatini, R., Auteri, P., Flace, P., Sisto, G., Montagnani, M., ... Cagiano, R. (2007). Neurofunctional effects of developmental sodium Fl exposure in rats. European Review for Medical and Pharmacological Sciences, 11, 211-224.

Berkels, R., Purol-Schnabel, S., \& Roesen, R. (2004). Measurement of nitric oxide by reconversion of nitrate/nitrite to NO. Methods in Molecular Biology, 279, 1-8.

Beutler, E., and West, C. (1978). Glucose-6-phosphate dehydrogenase variants in the chimpanzee. Biochem. Med. 20364

Bhatnagar, M., Rao, P., \& Sushma, J. (2002). Neurotoxicity of Fl: Neurodegeneration in hippocampus of female mice. Indian Journal of Experimental Biology, 40, 546-554.

Birkel, J. M. (1970). Direct potentiometric determination of fluoride in soft tooth deposits. Caries Research, 4, 243-255.

Bolanos, J. P., Almeida, A., Stewart, V., Peuchen, S., Land, J. M., \& Clark, J. B. (1997). Nitric oxide-mediated mitochondrial damage in the brain: Mechanisms and implications for neurodegenerative diseases. Journal of Neurochemistry, 68 , $2227-2240$

Bouaziz, H., Ben Amara, I., Essefi, M., Croute, F., \& Zeghal, N. (2010). Flinduced brain damages in suckling mice. Pesticide Biochemistry and Physiology, 96, 24-29.

Cabrera, C., Artacho, R., \& Gimenez, R. (2006). Beneficial effects of green tea - A review. Journal of the American College of Nutrition, 25, 79-99.

Chinoy, N. J. (1991). Effects of sodium Fl on physiology of some animals and human beings. Pesticide Biochemistry and Physiology, 1, 17-32.

Chlubek, D, Poland S., 2003. Fl and oxidative stress. FI 36., 217-228.

Choi, D. Y., Lee, Y. J., Hong, J. T., \& Lee, H. J. (2012). Antioxidant properties of natural polyphenols and their therapeutic potentials for Alzheimer's diseases. Brain Research Bulletin, 87(2-3), 144-153.

Chomczynski, P., \& Sacchi, N. (1987). Single step method of RNA isolation by acid guanidinium thiocyanatephenol-chloroform extraction. Analytical Biochemistry, 162, 156-159.

Chong, Z. Z., Li, F., \& Maiese, K. (2005). Oxidative stress in the brain: Novel cellular tar-gets that govern survival during neurodegenerative disease. Progress in Neurobiology, 75, 207-246

Ellman, G. L. (1959). Tissue sulfhydryl groups. Archives of Biochemistry and Biophysics, 82, 70-77.

Ellman, G. L., Courtney, K. D., Andres, V., \& Featherstone, R. M. (1961). A new and rapid colorimetric determination of acetylcholinesterase activity. Biochemical Pharmacology, 7, 88-95.

Eraslan, G., Kanbur, M., \& Silici, S. (2007). Evaluation of propolis effects on some biochemical parameters in rats treated with sodium FI. Pesticide Biochemistry and Physiology, 88, 273-283.

Flora, S. J., Mittal, M., \& Mishra, D. (2009). Co-exposure to arsenic and fluoride on oxidative stress., glutathione linked enzymes., biogenic amines and DNA damage in mouse brain. Journal of the Neurological Sciences, 285, 198-205.

Gutteridge, J. M. C. (1995). Lipid peroxidation and antioxidants as biomarkers of tissue damage. Clinical Chemistry, 41, 1819-1828.

Habig, W. H., Pabst, M. J., \& Jakpoly, W. B. (1974). Glutathione transferase: A first enzymatic step in mercapturic acid formation. The Journal of Biological Chemistry, 249, 7130-7139.

Hofmann, M. A., Schiekofer, S., \& Isermann, B. (1999). Peripheral blood mononuclear cells isolated from patients with diabetic nephropathy show increased activation of the oxidative stress sensitive transcription factor NFkB. Diabetologia, 42, 222-232.

Horn, H. D., \& Burns, F. H. (1978). Assay of glutathione reductase activity. In H. V. Bergmeyer (Ed.), Methods of enzymatic analysis, (pp. 142-146). New York: Academic Press.
Hsu, S. M., Raine, L., \& Fanger, H. (1981). Use of avidin-biotin-peroxidase complex $(A B C)$ in immunperoxidase techniques: A comparison between $A B C$ and unlabeled antibody (PAP) procedures. The Journal of Histochemistry and Cytochemistry, 29, 577-580.

Jacobwitz, D. M., \& Richardson, S. J. (1978). Method for the rapid determination of norepinephrine., dopamine., and serotonin in the same brain region. Pharmacology, Biochemistry, and Behavior, 8, 515.

Joels, M. (2008). Functional actions of corticosteroids in the hippocampus. European Journal of Pharmacology, 583(2-3), 312-321.

Jones, D. P. (2002). Redox potential of GSH/GSSG couple: Assay and biological significance. Methods in Enzymology, 348, 93-112.

Kakkar, P., Das, B., \& Viswanathan, P. N. (1984). A modified spectrophotometric assay of superoxide dismutase. Indian Journal of Biochemistry \& Biophysics, 21 , 130-132.

Kim, C. Y., Lee, C., Park, G. H., \& Jang, J. H. (2009). Neuroprotective effect of epigallocatechin-3-gallate against beta-amyloid-induced oxidative and nitrosative cell death via augmentation of antioxidant defense capacity. Archives of Pharmacal Research, 32(6), 869-881.

Kumar, P., \& Kumar, A. (2009). Protective effects of epigallocatechin gallate following 3-nitropropionic acid-induced brain damage: Possible nitric oxide mechanisms. Psychopharmacology, 207, 257-270.

Lee, J. H., Jung, J. Y., Jeong, J. Y., Park, J. H., Yang, K. H., \& Choi, N. K. (2008). Involvement of both mitochondrial- and death receptor-dependent apoptotic pathways regulated by $\mathrm{Bcl}-2$ family in sodium Fl-induced apoptosis of the human gingival fibroblasts. Toxicology, 243, 340-347.

Lee, S. R., Kim, S. P., \& Kim, J. E. (2000). Protective effect of topiramate against hippocampal neuronal damage after transient global ischemia in the gerbils. Neuroscience Letters, 281, 184-187.

Levine, R. L., Garland, D., \& Oliver, C. N. (1990). Determination of carbonyl content in oxidatively modified proteins. Methods in Enzymology, 186, 464-478.

Lu, G., Lu, X., \& Jing, L. (2000). Hepatocyte and neuron apoptosis induced by chronic fluorosis in rats. Flu, 33, 14-15.

Li, Y. M., Heerema, N. A., \& Dunipace, A. J. (1987). Genotoxic effects of FI evaluated by sister chromatid exchange. Mutation Research, 192, 191-201.

Locksley, R. M., Killeen, N., \& Lenardo, M. J. (2001). The TNF and TNF receptor superfamilies: Integrating mammalian biology. Cell, 104, 487-501.

Long, Y. G., Wang, Y. N., Chen, J., Jiang, S. F., Nordberg, A., \& Guan, Z. Z. (2002). Chronic FI toxicity decreases the number of nicotinic acetylcholine receptors in rat brain. Neurotoxicology and Teratology, 24, 751-757.

Lowry, O. H., Rosebrough, N. J., Farr, A. L., \& Randall, R. J. (1951). Protein measurement with Folin phenol reagent. J Biol Chem, 193(1), 265-275.

Madhusudhan, N., Basha, P. M., Begum, S., \& Ahmed, F. (2009). Fl-induced neuronal oxidative stress and its amelioration by antioxidants in developing rats. Flu., 42, 179-187.

McCord, JM, Keele, BB, Fridovich, I, 1976. An enzyme based theory of obligate anaerobis: The physiological functions of superoxide dismutase. Proceedings of the National Academy of Sciences of the United States of America 68. 1024-1031.

Miltonprabu, S., \& Thangapandiyan, S. (2013). Protective effect of epigallocatechin gallate on fl-induced oxidative stress related haematotoxicity in rats. Research Reviews, 1, 2

Ming, Z, Aiguo, W, Tao, X, Ping, H, 2008. Effects of Fl on DNA damage., S-phase cell-cycle arrest and the expression of NF-kB in primary cultured rat hippocampal neurons. Toxicology Letters. 179., (1)1-5.

Mullenix, P. J., Denbensten, P. K., Sehunior, A., \& Kernan, W. J. (1995). Neurotoxicity on NaF in rats. Neurotoxicology and Teratology, 7, 169-177.

Mullenix, P. J., Denbesten, P. K., Schunior, A., \& Kernan, W. J. (1995). Neurotoxicty of sodium $\mathrm{Fl}$ in rats. Neurotoxicology and Teratology, 17, 169-177.

$\mathrm{Na}$, H. K., \& Surh, Y. J. (2008). Modulation of Nrf2-mediated antioxidant and detoxifying enzyme induction by the green tea polyphenol EGCG. Food and Chemical Toxicology, 46, 1271-1278.

Nabavi, S. F., Eslami, S., Moghaddam, A. H., \& Nabavi, S. M. (2011). Protective effects of curcumin against Fl-induced oxidative stress in the rat brain. Neurophysiology, 43, 287-291.

Nabavi, S. M., Sureda, A., Nabavi, S. F., Latifi, A. M., Moghaddam, A. H., \& Hellio, C. (2012). Neuroprotective effects of silymarin on sodium Fl-induced oxidative stress. Journal of Fluorine Chemistry, 142, 79-82.

National Research Council., 2006. Fl in drinking water: A scientific review of EPA's standards. National Academies Press., Washington D.C. p 186. 
Niehiaus, W. G., \& Samuelsson, D. (1968). Formation of malondialdehyde from phospholipids arachidonate during microsomal lipid peroxidation. European Journal of Biochemistry., 6, 126-130.

Omaye, S. T., Turnbull, J. D., \& Sauberlich, H. E. (1979). Selected methods for the determination of ascorbic acid in animal cells., tissues and fluids. Methods in Enzymology, 62, 3-11.

Pratap Reddy, K., Sailaja, G., \& Krishnaiah, C. (2009). Protective effects of selenium on Fl induced alterations in certain enzymes in brain of mice. Journal of Environmental Biology, 30(5), 859-864.

Rotruck, J. T., Rope, A. L., \& Ganther, H. F. (1973). Selenium: Biochemical role as a component of glutathione peroxidase. Science, 179, 588-590.

Russell, L. B. (2004). Excitotoxicity: A possible central mechanism in fluoride neurotoxicity. Fluoride, 37(4), 301-314.

Salvesen, G. S., \& Riedl, S. J. (2009). Structure of the Fas/FADD complex: A conditional death domain complex mediating signaling by receptor clustering. Cell Cycle, 8(17), 2723-2727.

Selvakumar, K., Bavithra, S., Suganthi, M., Benson, C. S., Elumalai, P., Krishnamoorthy, R. G., ... Arunakaran, J. (2012). Protective role of quercetin on PCBs-induced oxidative stress and apoptosis in hippocampus of adult rats. Neurochemical Research, 37, 708-721.

Shanthakumari, D., Srinivasalu, S., \& Subramanian, S. (2004). Effect of FI intoxication on lipid peroxidation and antioxidant status in experimental rats. Toxicology, 204, 219-228.

Sinha, A. K. (1972). Colorimetric assay of catalase. Annals of Biochemistry, 47, 389-394.

Strasser, A., Jost, P. J., \& Nagata, S. (2009). The many roles of FAS receptor signalling in the immune system. Immunity, 30(2), 180-192.

Thangapandiyan, S., \& Miltonprabu, S. (2013). Epigallocatechin gallate effectively ameliorates FI induced oxidative stress., DNA damage in the liver of rats. Canadian Journal of Physiology and Pharmacology, 91, 528-537.

Thangapandiyan, S., \& Miltonprabu, S. (2014). Epigallocatechin gallate supplementation protects against renal injury induced by $\mathrm{Fl}$ intoxication in rats: Role of Nrf2/HO-1 signaling. Toxicology Reports, 1, 12-30.

Thangapandiyan, S., Miltonprabu, S., \& Senthilraja, P. (2016). Epigallocatechin gallate potentially abrogates fluoride induced lung oxidative stress. inflammation via Nrf2/Keap 1 signaling pathway in rats. An in-vivo and insilico study. International Immunology Pharmacology, 39, 128-129.

Tokunaga, T., Morshed, S. R., Otsuki, S., Takayama, F., Hashimoto, K., Kashimata, M., ... Sakagami, H. (2003). Effect of endodontic agents on cytotoxicity induction by sodium fl. In Vivo, 17, 583-591.

Tsuruta, T., Oh-hashi, K., Kiuchi, K., \& Hirata, Y. (2008). Degradation of caspaseactivated DNase by the ubiquitineproteasome system. Biochimica et Biophysica Acta, 1780(5), 793-799.

Vani, M. L., \& Reddy, K. P. (2000). Effects of Fl accumulation on some enzymes of brain and gastronemius muscle of mice. Flu., 33, 17-26.

Varner, J. A., Jensen, K. F., Horvath, W., \& Isaacson, R. L. (1998). Chronic administration of aluminum-Fl or sodium-Fl to rats in drinking water: Alterations in neuronal and cerebrovascular integrity. Brain Research, 784(1-2), 284-298.

Vrablic, A. S., Albright, C. D., Craciunescu, C. N., Salganik, R. I., \& Zeisel, S. H. (2001). Altered mitochondrial function and overgeneration of reactive oxygen species precede the induction of apoptosis by 1-0-octadecyl-2-methyl-racglycero-3- phosphocholine in p53-defective hepatocytes. The FASEB Journal, $15,1739-1744$

\section{Submit your manuscript to a SpringerOpen ${ }^{\circ}$ journal and benefit from:}

- Convenient online submission

- Rigorous peer review

- Open access: articles freely available online

- High visibility within the field

- Retaining the copyright to your article

Submit your next manuscript at $\gg$ springeropen.com 